\title{
Single-Atom Tungsten Doped Nis0.5Se0.5 \\ Nanosheets@Nanorods Heterostructures Catalyze Water Splitting Highly Active and Durable
}

\section{Yang Wang}

Tianjin University

Xiaopeng Li

Tianjin University

Mengmeng Zhang

Tianjin University

Jinfeng Zhang

Tianjin University

\section{Zelin Chen}

Hainan University

Xuerong Zheng

Tianjin University https://orcid.org/0000-0002-0161-4077

Naiqin Zhao

Tianjin University

Zhangliu Tian

National University of Singapore

Xiaopeng Han

Tianjin University https://orcid.org/0000-0002-7557-7133

Karim Zaghib

Hydro-Quebec

\section{Yuesheng Wang}

Hydro-Québec https://orcid.org/0000-0001-7269-9015

\section{Yida Deng ( $\nabla$ yida.deng@tju.edu.cn )}

Tianjin University

wenbin $\mathrm{Hu}$

Tianjin University

\section{Article}

Keywords: electrocatalysts, hydrogen/oxygen evolution reaction, water splitting 
Posted Date: July 13th, 2021

DOl: https://doi.org/10.21203/rs.3.rs-681994/v1

License: (c) (i) This work is licensed under a Creative Commons Attribution 4.0 International License. Read Full License 
14 single-atom, thus increasing the electron density of $\mathrm{Ni} 2 \mathrm{p}$ orbital, optimizing the

15 adsorption/desorption process of $\mathrm{H}$, significantly reducing the energy barrier of the rate-

6 determining step $\left(\mathrm{O}^{*} \rightarrow \mathrm{OOH}^{*}\right)$, finally accelerating thermodynamics and kinetics of HER/OER.

17 This work provides a rational feasible strategy to design single-atom catalysts for water splitting Nanosheets@Nanorods Heterostructures Catalyze Water Splitting Highly Active and Durable

\section{Abstract}

Developing robust nonprecious electrocatalysts towards hydrogen/oxygen evolution reaction (HER/OER) is crucial for the spread of hydrogen energy industrialization. Here, we prepared a highly active and durable electrocatalyst of $\mathrm{W}$ single-atoms doped $\mathrm{NiS}_{0.5} \mathrm{Se}_{0.5}$ nanosheets@ $\mathrm{NiS}_{0.5} \mathrm{Se}_{0.5}$ nanorods heterostructure $\left(\mathrm{W}-\mathrm{NiS}_{0.5} \mathrm{Se}_{0.5}\right)$. The $\mathrm{W}-\mathrm{Ni} \mathrm{S}_{0.5} \mathrm{Se}_{0.5}$ exhibits superior catalytic activity for HER and OER with an ultralow overpotential $(39,106 \mathrm{mV}$ for HER and 171, $239 \mathrm{mV}$ for OER) and excellent long-term durability (500 h) at 10 and $100 \mathrm{~mA}$ $\mathrm{cm}^{-2}$, outperforming commercial precious-metal catalysts and many other reported transitionmetal-based compounds. The spin state of $\mathrm{Ni}$ was delocalized by introducing low spin-state of $\mathrm{W}$ single-atom, thus increasing the electron density of $\mathrm{Ni} 2 \mathrm{p}$ orbital, optimizing the adsorption/desorption process of $\mathrm{H}$, significantly reducing the energy barrier of the rate-

Single-Atom Tungsten Doped Nis ${ }_{0.5} \mathrm{Se}_{0.5}$ 
1 and develop advanced transition metal-based electrocatalysts via regulating delocalized spin

2 states.

\section{Introduction}

4 The ever-increasing energy and environmental issues are obliging us to develop sustainable

5 and clean energy technologies. Electrochemical water splitting into hydrogen, as the advantages

6 of readily available reactant, stable output, and feasibility of large-scale production, has long

7 been believed to be a promising energy storage strategy to solve the intermittence of renewable

8 energy $^{1-5}$. However, the large overpotential caused by kinetically sluggish oxygen evolution

9 reaction (OER) and hydrogen evolution reaction (HER) largely hinder its practical application ${ }^{6-8}$.

10 Nowadays, noble-based materials ( $\mathrm{Pt}$ and $\mathrm{Ru} / \mathrm{IrO}_{2}$ ) have been regarded as benchmark

11 electrocatalysts to reduce the overpotential of reactions ${ }^{9-11}$. From a commercialization point-of-

12 view, it is highly imperative to develop the cost-efficient and robust electrocatalysts to substitute

13 for noble-metal materials, especially based on earth-abundant materials ( $\mathrm{Fe}, \mathrm{Co}$, $\mathrm{Ni}$ et al. $)^{12-14}$.

14 Transition metal compounds (TMCs) have been widely studied as one of important candidates

15 for the water splitting due to their environmental benignity, low cost-efficiency, and theoretically

16 high catalytic activity ${ }^{15,16}$. However, the water-splitting catalytic performances of pure TMCs are

17 far from satisfactory. Previous experimental and theoretical work ${ }^{17,18}$ has anticipated that the

18 incorporation of metal atoms has been considered to be a valid strategy to optimize

19 synergistically the active sites and dynamics, which can adequately improve water splitting

20 activity in transition-metal compounds. For example, Xie et al. ${ }^{19}$ have confined Mn atoms in the 
$1 \mathrm{CoSe}_{2}$ ultrathin nanosheets and inducing a subtle distortion of atomic arrangement. The spin

2 states of heteroatom $\mathrm{Mn}$ cause this distortion and form a suitable structure to boost HER

3 performances. Inevitably, the heteroatoms with spin states in the crystal lattice would generate a

4 lopsided Coulomb force and then emerge micro-mechanically derived disturbance, which results

5 in a subtle distortion of the atomic arrangement and finally improve electrocatalytic activity ${ }^{20,21}$.

6 Moreover, heteroatoms can manipulate the electronic structure of electrocatalysts and accelerate

7 the kinetic energy barrier in the HER/OER process ${ }^{22,23}$. More importantly, the distortion degree

8 and electronic structure could be expediently and availably adjusted by the doping foreign atoms.

9 Single-atom catalysts (SACs), with maximum atom efficiency and coordinatively unsaturated

10 active sites, have been drawn wide attention in facilitating the electrocatalytic activity ${ }^{24-26}$.

11 However, the operating durability of SACs remains a challenge. Single-atom doping has been

12 reported to be useful for assisting suitable sites for intermediates formation with enhancing the

13 interaction between individual metal atoms and the supports ${ }^{27-30}$. Thus, it is urgent to propose a

14 strategy that combines the high efficiency of SACs into the crystal lattice and the delocalized

15 spin states of transition metals, which can realize the design of an efficient and stable HER/OER

16 electrocatalyst. W, a promising candidate of the SACs, features exceptional properties of positive

17 charge, large spin magnetic moment, and excellent electrical conductivity ${ }^{31-33}$. However, the W

18 single-atoms employed in water splitting remain unexplored, and thus, revealing the function of

19 which in TMCs and corresponding catalytic mechanism is extremely important. 
$1 \quad$ Herein, a low spin state $\mathrm{W}$ single-atom doped $\mathrm{NiS}_{0.5} \mathrm{Se}_{0.5}$ nanosheet@ $\mathrm{NiS}_{0.5} \mathrm{Se}_{0.5}$ nanorods

2 heterostructure grown on nickel foam (NF), denoted as $\mathrm{W}-\mathrm{NiS}_{0.5} \mathrm{Se}_{0.5}$, was prepared by a

3 convenient and facile method. The $\mathrm{W}-\mathrm{NiS}_{0.5} \mathrm{Se}_{0.5}$ delivers high activity and excellent stability for

4 HER and OER, outperforming commercial $\mathrm{Pt} / \mathrm{C}$, $\mathrm{IrO}_{2}$, and many recently reported transition

5 metal-based electrocatalysts. In detail, the strong connection between $\mathrm{W}$ atoms and $\mathrm{S} / \mathrm{Se}$ atoms

6 in $\mathrm{NiS}_{0.5} \mathrm{Se}_{0.5}$ contributes to the exceptional stability, while some additional adsorption sites

7 provided by $\mathrm{W}$ facilitate the HER/OER process. Moreover, the spin state of $\mathrm{W}$ single-atom

8 would cause delocalization spin states of the $\mathrm{Ni}$, increase electronic density of $\mathrm{Ni} 2 \mathrm{p}$-electron,

9 improve $\mathrm{H}$ adsorption/desorption behavior, significantly reduce the energy barrier of the rate-

10 determining step $\left(\mathrm{O}^{*} \rightarrow \mathrm{OOH}^{*}\right)$. We also demonstrate the universality of synthesized $\mathrm{W}$ single-

11 atom on $\mathrm{NiS}_{0.5} \mathrm{Se}_{0.5}$ strategy that can also be extended to obtained $\mathrm{W}$-based single-atom on other

12 TMCs materials such as NiS, NiSe, and their HER/OER activity is significantly enhanced. We

13 believe that this study will pave a promising way to design high active and stable non-precious-

14 metal catalysts to split water.

\section{Results}

16 Material synthesis and characterization. To investigate the formation process of $\mathrm{W}$ -

$17 \mathrm{NiS}_{0.5} \mathrm{Se}_{0.5}$, different reaction time were investigated. As shown in Supplementary Figs. 1,2 and

18 Supplementary Table 1, at the first stage, the interconnected NiS nanorods were formed. Then

19 reacting with $\mathrm{Se}^{2-}$ and generates agglomerated $\mathrm{NiS}_{0.75} \mathrm{Se}_{0.25}$ nanorods ${ }^{34}$. Subsequently, continue

20 to selenizing and produce $\mathrm{NiS}_{0.5} \mathrm{Se}_{0.5}$ nanorods. At the fourth stage, the $\mathrm{Ni}^{2+}, \mathrm{S}^{2-}$, and $\mathrm{Se}^{2-}$ in the 
1 solution would form the nanosheet and wrapping the $\mathrm{NiS}_{0.5} \mathrm{Se}_{0.5}$ nanorods due to the principle of

2 lattice match, which is consistent with our previous report ${ }^{35}$. Finally, the $\mathrm{W}$ atoms substitute $\mathrm{Ni}$

3 atoms in $\mathrm{NiS}_{0.5} \mathrm{Se}_{0.5}$ nanosheets and the $\mathrm{W}$ single-atom- $\mathrm{NiS}_{0.5} \mathrm{Se}_{0.5}$ nanosheets wrapped

$4 \mathrm{NiS}_{0.5} \mathrm{Se}_{0.5}$ nanorods heterogeneous structure is formed (Fig. 1a). The $\mathrm{W}$ element has a more

5 unoccupied outermost electron orbital than $\mathrm{Ni}$, and the replacement of one $\mathrm{Ni}$ by one $\mathrm{W}$ the

$6 \mathrm{NiS}_{0.5} \mathrm{Se}_{0.5}$ nanosheets structure was expected to generate some additional adsorption sites on $\mathrm{W}$.

7 To verify the inevitability of forming $\mathrm{W}-\mathrm{NiS}_{0.5} \mathrm{Se}_{0.5}$, we calculated the formation energy of $\mathrm{W}-$

$8 \mathrm{NiS}_{0.5} \mathrm{Se}_{0.5}, \mathrm{NiS}_{0.5} \mathrm{Se}_{0.5}, \mathrm{NiS}, \mathrm{NiS}-\mathrm{NiS}_{0.5} \mathrm{Se}_{0.5}$, and W-NiS-NiS $\mathrm{S}_{0.5} \mathrm{Se}_{0.5}$ (Supplementary Fig. 3). W-

$9 \mathrm{NiS}_{0.5} \mathrm{Se}_{0.5}$ and $\mathrm{NiS}_{0.5} \mathrm{Se}_{0.5}$ show lower formation energy than other phases, indicating the

10 accessibility and feasibility of producing these phases. Supplementary Fig. 4 showed the XRD

11 patterns of the prepared samples. For bare $\mathrm{NiS}_{0.5} \mathrm{Se}_{0.5}$, all peaks were assigned to the same crystal

12 structures of pyrite-type NiSe (JCPDS No. 02-0892) and NiS (JCPDS No. 02-1280), which have

13 been investigated in our previous reports ${ }^{35}$. The $\mathrm{W}$-doped sample $\left(\mathrm{W}-\mathrm{NiS}_{0.5} \mathrm{Se}_{0.5}\right)$ also present

14 same typical XRD pattern of $\mathrm{NiS}_{0.5} \mathrm{Se}_{0.5}$, no peaks of $\mathrm{WS}_{2}, \mathrm{WSe}_{2}$ or $\mathrm{WO}_{3}$, which can be

15 attributed to the low concentration and single-atom W. From the scanning electron microscopy

16 (SEM) images, the uniformly nanorods with $\sim 260 \mathrm{~nm}$ grown on NF (Fig. $1 \mathrm{~b}$ and Supplementary

17 Fig. 5). From the transmission electron microscopy (TEM) images, the nanorods were wrapped

18 with ultrathin nanosheets (Fig. 1c). The wrapped nanosheet structure makes the W-NiS $\mathrm{S}_{0.5} \mathrm{Se}_{0.5}$

19 nanosheets suspended and fully immersed in the electrolyte solution, which makes the electrolyte

20 solution flow more freely without dead space around the $\mathrm{W}-\mathrm{NiS}_{0.5} \mathrm{Se}_{0.5}$ nanosheets and is thus 
1 beneficial to the transfer and access of the electrolyte ions. In the high-resolution TEM (HRTEM)

2 image (Fig. 1d), the lattice fringe of nanorod is $0.20 \mathrm{~nm}$ corresponding to (102) lattice plane of

$3 \mathrm{NiS}_{0.5} \mathrm{Se}_{0.5}$. The lattice spacing of $0.27 \mathrm{~nm}$ in the nanosheets can be indexed to the (101) crystal

4 plane, which similar to the pure $\mathrm{NiS}_{0.5} \mathrm{Se}_{0.5}$. Neither nanoparticles nor clusters were found in the

5 HRTEM images of nanosheet and nanorods. High-angle annular dark-field scanning TEM

6 (HAADF-STEM) measurements were adopted to directly observe the presence of $\mathrm{W}$ on the

7 surface of $\mathrm{NiS}_{0.5} \mathrm{Se}_{0.5}$ nanosheets. As Fig. 1e,f shown, single-atom W appearing as bright spots

8 can be found to be well dispersed in the lattice of $\mathrm{NiS}_{0.5} \mathrm{Se}_{0.5}$, confirming the formation of single-

9 atom dispersed catalyst. Similarly, the different intensity and the loosely interatomic distances of

10 line profiles also indicate the isolated W atoms (Supplementary Fig. 5). As seen from the cross-

11 section view, the $\mathrm{W}$ single-atom doped into the nanosheets of $\mathrm{W}-\mathrm{NiS}_{0.5} \mathrm{Se}_{0.5}$ rather than nanorods

12 (Fig. 1g), while the Ni, S, and Se elements are homogeneously distributed in the whole cross-

13 section. The specific concentration of $\mathrm{W}$ is detected by inductively coupled plasma (ICP) and the

14 atomic ratio of $\mathrm{W}$ to $\mathrm{Ni}$ is 3.06: 96.94, furthermore, a similar result can be received from energy

15 dispersive spectroscopy (EDX), while the ratio from X-ray photoelectron spectroscopy (XPS)

16 were obvious higher than those of ICP and EDX (Supplementary Fig. 5d and Table 2). It

17 demonstrated the formation of $\mathrm{W}-\mathrm{NiS}_{0.5} \mathrm{Se}_{0.5}$ nanosheets $/ \mathrm{NiS}_{0.5} \mathrm{Se}_{0.5}$ nanorods heterostructures,

18 which will improve its electrocatalytic HER/OER performance ${ }^{36-38}$. Particularly, our strategy can

19 also be popularized to synthesize other W single-atom modified TMCs, such as NiS and NiSe

20 (Supplementary Fig. 7,8 and Table 3). 


\section{a}

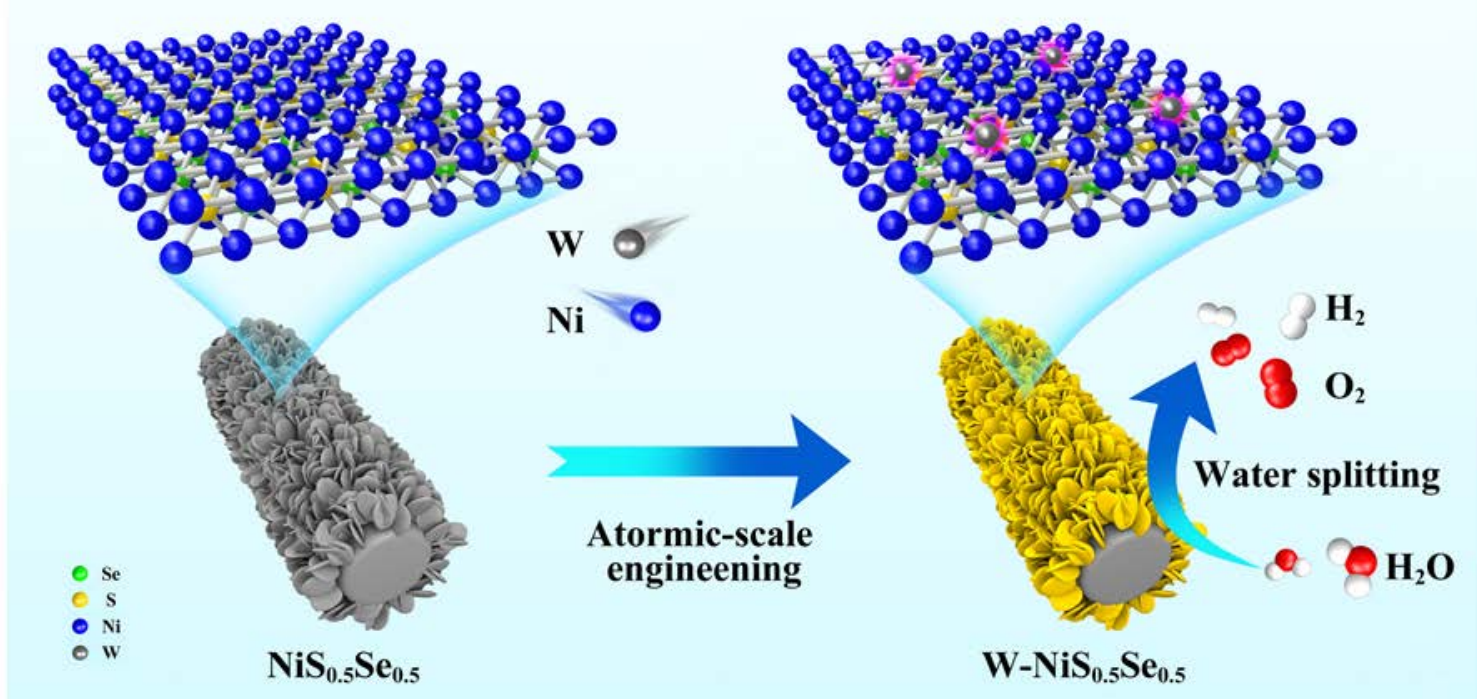

b

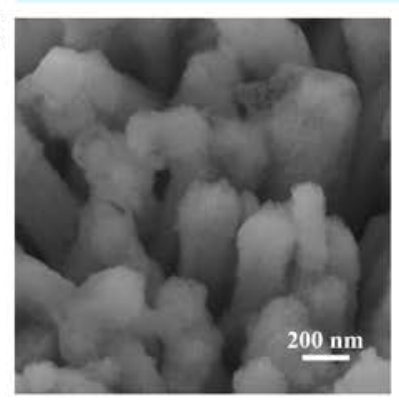

C
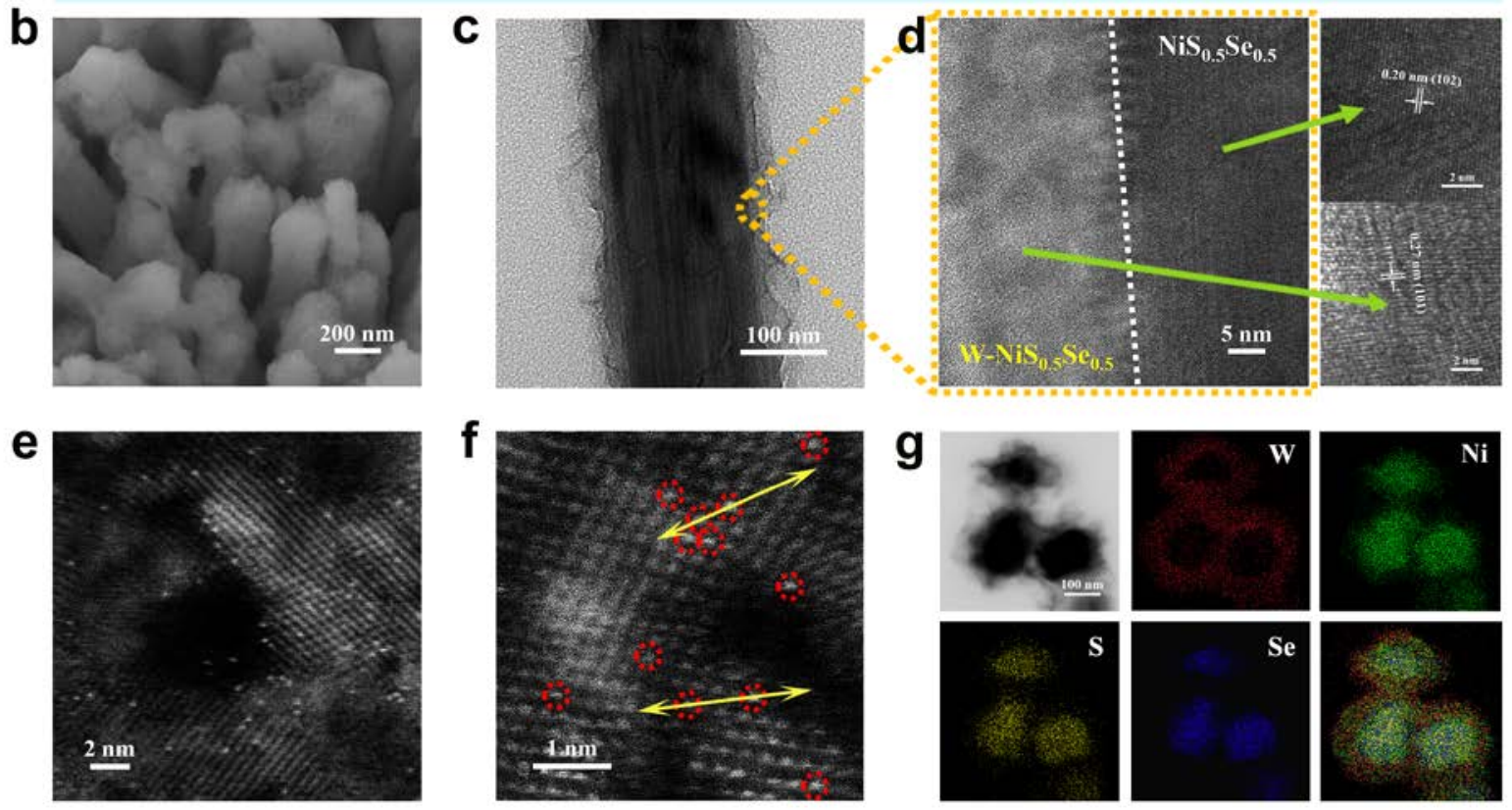

2 Fig. 1 Synthesized procedure and structural characterizations of W-NiS0.5Se0.5. (a)

3 Schematic illustration for the synthesis. (b) SEM image; (c, d) TEM images; (e, f) HAADF-

4 STEM image; (g) STEM-EDX elemental mapping images from the cross-section view.

5 XPS was performed to investigate the chemical composition and binding status of the catalysts.

6 The XPS survey spectrum of $\mathrm{W}_{-} \mathrm{NiS}_{0.5} \mathrm{Se}_{0.5}$ confirms the presence of $\mathrm{W}, \mathrm{Ni}, \mathrm{S}$, and $\mathrm{Se}$, 
1 suggesting the doping of $\mathrm{W}$ in $\mathrm{NiS}_{0.5} \mathrm{Se}_{0.5}$ (Supplementary Fig. 9). Fig. 2a shows the $\mathrm{W} 4 \mathrm{f}$ core-

2 level spectra of $\mathrm{W}_{-} \mathrm{NiS}_{0.5} \mathrm{Se}_{0.5}$ and $\mathrm{NiS}_{0.5} \mathrm{Se}_{0.5}$. The binding energy peaks identified for $\mathrm{W}$ -

$3 \mathrm{NiS}_{0.5} \mathrm{Se}_{0.5}$ at $34.7 \mathrm{eV}$ and $33.1 \mathrm{eV}$ can be assigned to $\mathrm{W}^{4+} 4 \mathrm{f}_{5 / 2}$ and $4 \mathrm{f}_{7 / 2} 39$. Moreover, the peaks

4 of $\mathrm{W}^{6+} 4 \mathrm{f}_{5 / 2}$ at $37.7 \mathrm{eV}$ and $4 \mathrm{f}_{7 / 2}$ at $35.6 \mathrm{eV}^{40,41}$, which were attributed to surface oxidation of the

$5 \quad \mathrm{~W}-\mathrm{NiS}_{0.5} \mathrm{Se}_{0.5}{ }^{42,43}$. Compared with $\mathrm{NiS}_{0.5} \mathrm{Se}_{0.5}$, a slight negative shift of the binding energy was

6 observed for $\mathrm{W}_{-} \mathrm{NiS}_{0.5} \mathrm{Se}_{0.5}$ in Ni $2 \mathrm{p}$ spectra (Fig. 2b), which indicates an increased electron

7 density of Ni cations after $\mathrm{W}$ introducing, thus enhancing the electrocatalytic performance ${ }^{44,45}$.

8 X-ray absorption spectroscopy (XAS) was investigated to obtain in-depth insight into the

9 electronic and local structure of $\mathrm{W}-\mathrm{NiS}_{0.5} \mathrm{Se}_{0.5}$. Figs. $2 \mathrm{c}, \mathrm{d}$ exhibit $\mathrm{W} \mathrm{L}_{3}$-edge $\mathrm{X}$-ray absorption

10 near-edge structure (XANES) (Fig. 2c) and Fourier transform extended X-ray absorption fine

11 structure (FT-EXAFS) (Fig. 2d) spectra of $\mathrm{W}-\mathrm{NiS}_{0.5} \mathrm{Se}_{0.5}$, together with the $\mathrm{W}$ foil, commercial

$12 \mathrm{WS}_{2}, \mathrm{WSe}_{2}, \mathrm{WO}_{3}$. The main peak of $\mathrm{W}-\mathrm{NiS}_{0.5} \mathrm{Se}_{0.5}$ moves toward higher energy compared to $\mathrm{W}$

13 foil, $\mathrm{WS}_{2}$, and $\mathrm{WSe}_{2}$, but moves toward lower energy than that of $\mathrm{WO}_{3}$, indicating the different

14 chemical state of $\mathrm{W}$ (Supplementary Fig. 10). The $\mathrm{W} \mathrm{L}_{3}$-edge FT-EXAFS spectrum of W-

$15 \mathrm{NiS}_{0.5} \mathrm{Se}_{0.5}$ shows evident peaks at $1.26 \AA$, $1.87 \AA$, and $2.38 \AA$ (Fig. $2 \mathrm{~d}$ and Supplementary Fig.

16 11), which can be ascribed to W-O (1.34 ̊̊), W-S (1.93 $\mathrm{A})$, and W-Se (2.38 $\mathrm{A})$, respectively.

17 Compared to $\mathrm{W}$ foil, $\mathrm{WS}_{2}, \mathrm{WSe}_{2}$, and $\mathrm{WO}_{3}$, the absence of $\mathrm{W}-\mathrm{W}(2.67 \AA)$ in $\mathrm{W}-\mathrm{NiS}_{0.5} \mathrm{Se}_{0.5}$

18 indicates the atomic dispersion and special chemical coordination of $\mathrm{W}$. These results

19 demonstrate that single $\mathrm{W}$ atoms have been successfully doped into the $\mathrm{NiS}_{0.5} \mathrm{Se}_{0.5}$ nanosheets

20 via the substitution of $\mathrm{Ni}$ sites. In addition, an appreciable shift of W-O peak can be detected in 
1 W-NiS $\mathrm{S}_{0.5} \mathrm{Se}_{0.5}$ as compared with $\mathrm{WO}_{3}$, confirming the significantly different $\mathrm{W}-\mathrm{O}$ coordination.

2 This might be attributed the forming $\mathrm{W}-\mathrm{O}$ as the isolated $\mathrm{W}$ atoms adsorbed massive oxygen,

3 which was coincidence with previous reports ${ }^{46}$. Moreover, the XAS was used to uncover the

4 change of Ni species as the introduction of W. Fig. 2e shows the Ni K-edge XANES of W-

$5 \quad \mathrm{NiS}_{0.5} \mathrm{Se}_{0.5}$ and $\mathrm{NiS}_{0.5} \mathrm{Se}_{0.5}$. An obvious decreased intensity of the white line in the $\mathrm{W}-\mathrm{NiS}_{0.5} \mathrm{Se}_{0.5}$

6 implies the local atomic arrangement of $\mathrm{Ni}$ atom caused by single-atom $\mathrm{W}$ doping ${ }^{25,47}$. This

7 phenomenon is further definitely verified by the FT-EXAFS spectra (Fig. $2 \mathrm{f}$ and Supplementary

8 Fig. 12). More importantly, in comparison with the dominant peak of $\mathrm{W}-\mathrm{NiS}_{0.5} \mathrm{Se}_{0.5}$ shifts to a

9 lower value compared to that of $\mathrm{NiS}_{0.5} \mathrm{Se}_{0.5}$, indicating the contract of $\mathrm{Ni}-\mathrm{S}$ and $\mathrm{Ni}-\mathrm{Se}$ bonds in

$10 \mathrm{~W}-\mathrm{NiS}_{0.5} \mathrm{Se}_{0.5}$. The possible reason for this bonding change is the substitutional doped-W would

11 lead to the delocalization of $\mathrm{Ni}^{48,49}$.

12 The confinement of the distorted atomic arrangement to the basal plane can be further visually

13 confirmed by HRTEM and corresponding fast Fourier transform (FFT), as displayed in

14 Supplementary Fig. 13. The crystal lattice of $\mathrm{NiS}_{0.5} \mathrm{Se}_{0.5}$ shows a relatively regular atomic

15 arrangement. However, a subtly disordered atomic arrangement on the surface is observed as the

16 W single-atom doping into $\mathrm{NiS}_{0.5} \mathrm{Se}_{0.5}$. To directly estimate the disorder degree, similar to the

17 previous literature ${ }^{50,51}$, the rotational angle is introduced and which determined by two end points

18 of a diffraction arc and the central spot of the FFT. The disorder degree of 5.26\% and $15.93 \%$ for

$19 \mathrm{NiS}_{0.5} \mathrm{Se}_{0.5}$ and $\mathrm{W}-\mathrm{NiS}_{0.5} \mathrm{Se}_{0.5}$ is obtained, respectively. It can be reasonably predicted that this

20 distorted atomic arrangement is induced by the extraneous spin states. To reveal the spin state in 
$1 \quad \mathrm{~W}-\mathrm{NiS}_{0.5} \mathrm{Se}_{0.5}$, the temperature-dependent curve of magnetizations (M-T curve) was performed at

$2 \mathrm{H}=1 \mathrm{kOe}$ to detect the $e_{\mathrm{g}}$ electron configuration (Supplementary Fig. 14). The susceptibility is

3 derived from magnetizations $(\chi=\mathrm{M} / \mathrm{H})$ via the Curie-Weiss law and the total effective magnetic

4 moment $\left(\mu_{\mathrm{eff}}\right)$ is liner fitted from $\chi^{-1}-\mathrm{T}$ via $\mu_{\mathrm{eff}}=\sqrt{8 \mathrm{C}} \mu_{\mathrm{B}}^{52,53}$. According to obtained $\mu_{\mathrm{eff}}, e_{\mathrm{g}}$

5 filling for $\mathrm{NiS}_{0.5} \mathrm{Se}_{0.5}$ and $\mathrm{W}-\mathrm{NiS}_{0.5} \mathrm{Se}_{0.5}$ are 1.87 and 1.24 (Supplementary Fig. 14d), respectively,

6 indicating that the $\mathrm{W}-\mathrm{NiS}_{0.5} \mathrm{Se}_{0.5}$ has more $e_{\mathrm{g}}$ unoccupied states than the $\mathrm{NiS}_{0.5} \mathrm{Se}_{0.5}$. Given the

7 missing of high spin states, the $\mathrm{Ni}$ atoms in the $\mathrm{W}-\mathrm{NiS}_{0.5} \mathrm{Se}_{0.5}$ nanosheets with more unoccupied

$8 e_{\mathrm{g}}$ states should be caused by more delocalized than those in the $\mathrm{NiS}_{0.5} \mathrm{Se}_{0.5}$ (Supplementary Fig.

$9 \quad 14 \mathrm{e})$.
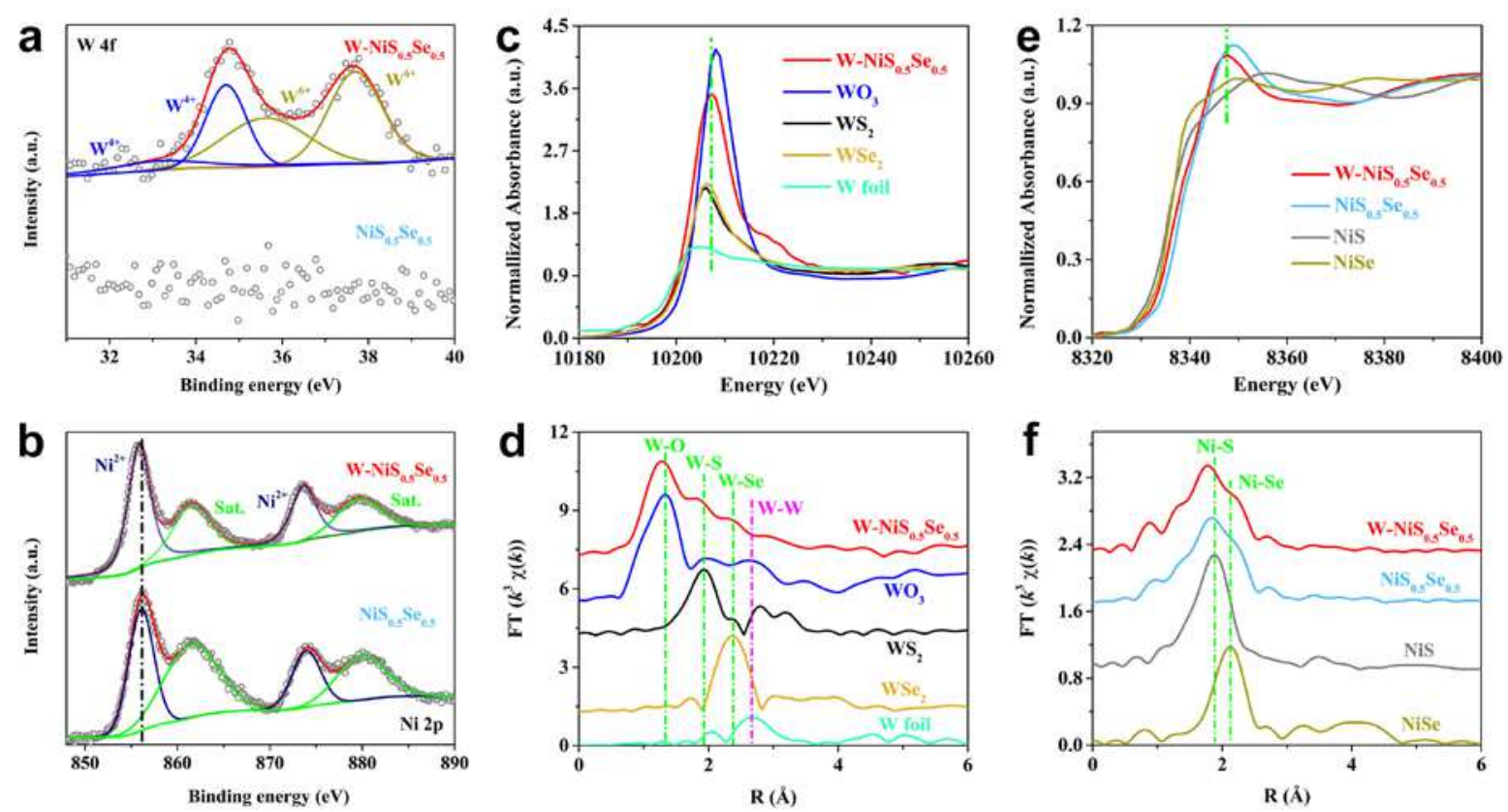

11 Fig. 2 Chemical state and atomic coordination characterizations of $\mathrm{W}-\mathrm{NiS}_{0.5} \mathrm{Se}_{0.5}$ and

12 NiS 0.5 Se0.5. The high-resolution XPS spectra of (a) W $4 \mathrm{f}$ and (b) Ni 2p. The XANES spectra of (c)

$13 \mathrm{~W} \mathrm{~L}_{3}$-edge and (f) the corresponding FT curves for $\mathrm{W}-\mathrm{NiS}_{0.5} \mathrm{Se}_{0.5}, \mathrm{NiS}_{0.5} \mathrm{Se}_{0.5}, \mathrm{WO}_{3}, \mathrm{WS}_{2}, \mathrm{WSe}_{2}$, 
1 and W foil. The XANES spectra of (e) Ni K-edge and (d) the corresponding FT curves for W-

$2 \quad \mathrm{NiS}_{0.5} \mathrm{Se}_{0.5}, \mathrm{NiS}_{0.5} \mathrm{Se}_{0.5}, \mathrm{NiS}$, and $\mathrm{NiSe}$.

3 Electrocatalytic HER performance. The HER performances of $\mathrm{W}-\mathrm{NiS}_{0.5} \mathrm{Se}_{0.5}, \mathrm{NiS}_{0.5} \mathrm{Se}_{0.5}, 20 \%$

4 commercial Pt/C, and NF were tested in $1.0 \mathrm{M} \mathrm{KOH}$ electrolyte with a three-electrode system.

5 As shown in Fig. 3a, W-NiS $0.5 \mathrm{Se}_{0.5}$ exhibits a lower overpotential of $39 \mathrm{mV}$ to reach $10 \mathrm{~mA} \mathrm{~cm}^{-2}$

6 at $5 \mathrm{mV} \mathrm{s}^{-1}$, which is comparable to commercial Pt/C $(36 \mathrm{mV})$ and much better than that of

$7 \quad \mathrm{NiS}_{0.5} \mathrm{Se}_{0.5}(72 \mathrm{mV})$ and $\mathrm{NF}(286 \mathrm{mV})$. The enhanced HER activity may result from the occurred

8 delocalization spin states of the $\mathrm{Ni}$ atoms as the single $\mathrm{W}$ atom doping into $\mathrm{NiS}_{0.5} \mathrm{Se}_{0.5}$.

9 Remarkably, W-NiS $\mathrm{S}_{0.5} \mathrm{Se}_{0.5}$ exhibits lower overpotentials to obtain the current densities of 10 ,

10100 , and $300 \mathrm{~mA} \mathrm{~cm}^{-2}$, especially at larger current density even surpass commercial Pt/C (Fig.

$113 \mathrm{~b}$ and Supplementary Table 4). The reaction kinetics of catalysts can be evaluated from the

12 corresponding Tafel plots and shown in Fig. 3c. The W-NiS $0.5 \mathrm{Se}_{0.5}$ shows a Tafel slope of $51 \mathrm{mV}$

$13 \mathrm{dec}^{-1}$, which is approximate to commercial $\mathrm{Pt} / \mathrm{C}\left(36 \mathrm{mV} \mathrm{dec}{ }^{-1}\right)$ and much lower than those of

$14 \mathrm{NiS}_{0.5} \mathrm{Se}_{0.5}\left(79 \mathrm{mV} \mathrm{dec}{ }^{-1}\right)$ and $\mathrm{NF}\left(161 \mathrm{mV} \mathrm{dec}{ }^{-1}\right)$. The lower Tafel slope of $\mathrm{W}-\mathrm{NiS}_{0.5} \mathrm{Se}_{0.5}$

15 demonstrates the construction of 3D heterostructured architectures and the doped W single-atom

16 can facilitate the HER kinetics. The above merits of the $\mathrm{W}-\mathrm{NiS}_{0.5} \mathrm{Se}_{0.5}$, including low

17 overpotential and Tafel slope, are superior to commercial Pt/C and many active non-noble metal

18 based electrocatalysts (Supplementary Table 5). Another powerful characterization for kinetics

19 estimation is electrical impedance spectroscopy (EIS) and displayed in Supplementary Fig. 15. 
1 The $\mathrm{W}-\mathrm{NiS}_{0.5} \mathrm{Se}_{0.5}$ shows a lower internal resistance and faster rapid charge transfer than those of

2 other catalysts, which due to the delocalized electronic state produced in $\mathrm{W}-\mathrm{NiS}_{0.5} \mathrm{Se}_{0.5}$. Clearly,

3 the $\mathrm{R}_{\mathrm{ct}}$ values show the rapid decrease from $\mathrm{NiS}_{0.5} \mathrm{Se}_{0.5}$ to W-NiS $\mathrm{S}_{0.5} \mathrm{Se}_{0.5}$ (Supplementary Table 4),

4 further confirming that the $\mathrm{W}$-doped sample had a relatively higher carrier mobility across the

5 Helmholtz layer, i.e., the catalyst|solution interface. The turnover frequency (TOF) of W-

$6 \mathrm{NiS}_{0.5} \mathrm{Se}_{0.5}$ can reach $1.105 \mathrm{~s}^{-1}$ at $-100 \mathrm{mV}_{\mathrm{RHE}}$, which is considerably higher than that of

7 commercial Pt/C $\left(0.222 \mathrm{~s}^{-1}\right), \mathrm{NiS}_{0.5} \mathrm{Se}_{0.5}\left(0.004 \mathrm{~s}^{-1}\right)$, and most reported non-noble catalysts (Fig.

$83 \mathrm{~d}$ and Supplementary Table 5). To deep clarify the enhanced activity, the electrochemical

9 double-layer capacitance $\left(\mathrm{C}_{\mathrm{dl}}\right)$ of catalysts was measured. Higher electrochemical surface area

10 (ECSA) implies more active sites for catalytic reactions and is good for water molecule

11 adsorption and intimate contact with the electrolyte ${ }^{54}$. As shown in Supplementary Fig. 16 and

12 Table 4, W-NiS $\mathrm{S}_{0.5} \mathrm{Se}_{0.5}$ exhibited the largest $\mathrm{C}_{\mathrm{dl}}$ of $138.6 \mu \mathrm{F} \mathrm{cm}{ }^{-2}$, which was higher than that of

$13 \mathrm{NiS}_{0.5} \mathrm{Se}_{0.5}\left(109.3 \mu \mathrm{F} \mathrm{cm}{ }^{-2}\right)$, which is attributed to the unique distorted atomic arrangement and

14 yields a significant excess of active sites. The normalized LSV from ECSA (Fig. 3e) indicates

15 the superior intrinsic HER activity in $\mathrm{W}-\mathrm{NiS}_{0.5} \mathrm{Se}_{0.5}$ than that in $\mathrm{NiS}_{0.5} \mathrm{Se}_{0.5}$, further evidencing

16 the enhancement effect of W single-atom dopant.

17 Apart from the HER performance, the stability is another pivotal factor for a promising

18 electrocatalyst. Cyclic voltammetry (CV) and chronopotentiometry measurements were

19 investigated to survey the stability of the $\mathrm{W}_{-\mathrm{NiS}} \mathrm{N}_{0.5} \mathrm{Se}_{0.5}$. In Fig. $3 \mathrm{f}, \mathrm{W}-\mathrm{NiS}_{0.5} \mathrm{Se}_{0.5}$ shows a

20 negligible degradation (only $39 \mathrm{mV}$ ) after operating for $500 \mathrm{~h}$ at $10 \mathrm{~mA} \mathrm{~cm}{ }^{-2}$, which is much 
1 better than commercial Pt/C. Especially, at the large current density of $100 \mathrm{~mA} \mathrm{~cm}{ }^{-2}, \mathrm{~W}-$

$2 \mathrm{NiS}_{0.5} \mathrm{Se}_{0.5}$ also shows a slight degradation of $58 \mathrm{mV}$. The robust durability of $\mathrm{W}-\mathrm{NiS}_{0.5} \mathrm{Se}_{0.5}$ can

3 be further verified by the LSV curves before and after 30,000 CV cycles. In order to evaluate the

4 structure stability of $\mathrm{W}-\mathrm{NiS}_{0.5} \mathrm{Se}_{0.5}$ during HER process, XRD, XPS, EDX, TEM, and STEM

5 after HER stability were performed (Supplementary Figs. 17-20 and Table 6). The results

6 demonstrate that $\mathrm{W}-\mathrm{NiS}_{0.5} \mathrm{Se}_{0.5}$ exhibits an extremely stable chemical phase and nanostructure.

7 This excellent stability may be caused by the high chemical stability, and high mechanical

8 stability of the catalyst materials, which mainly originate from their unique structure.
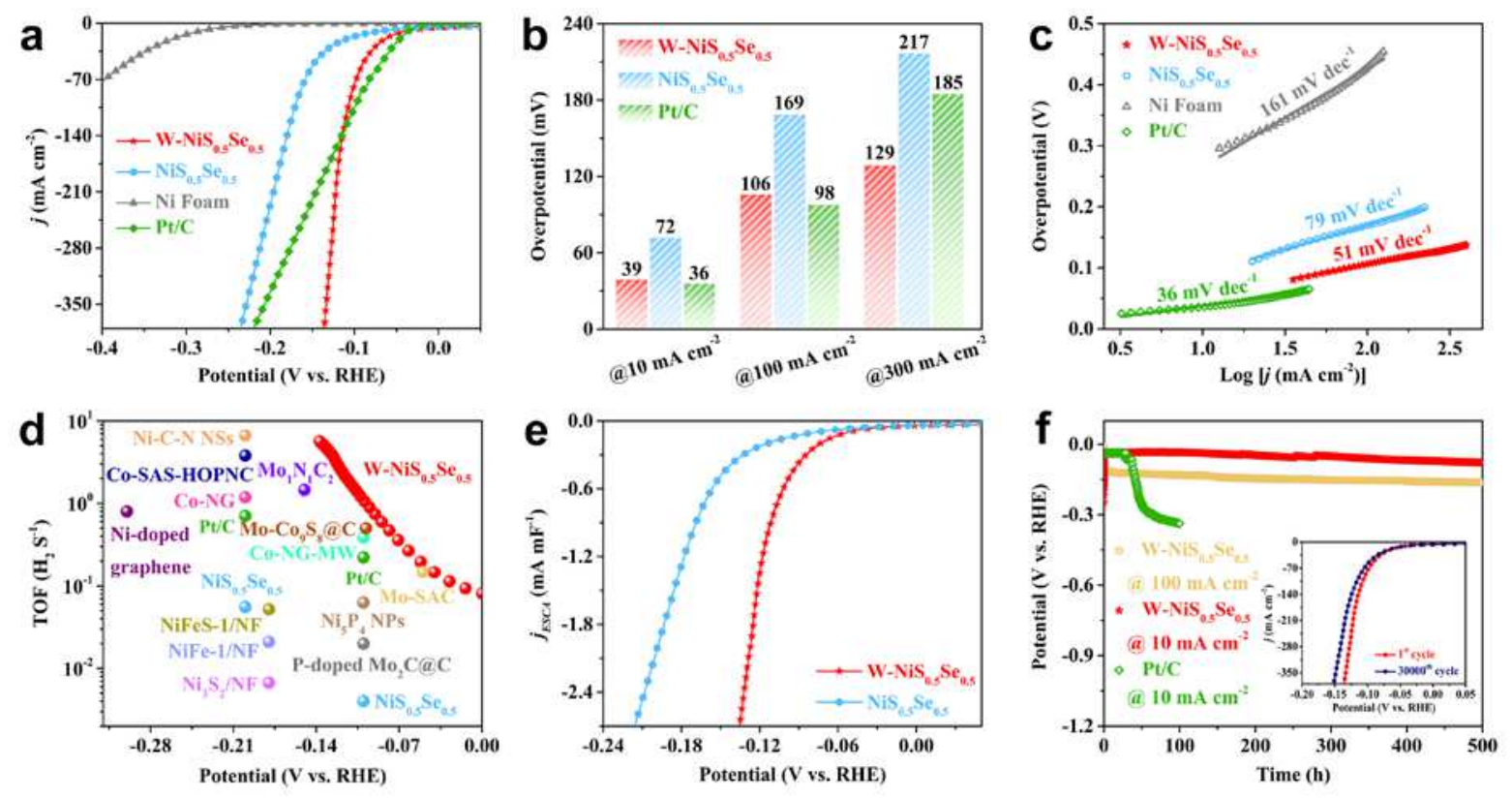

10 Fig. 3 Electrocatalytic HER properties of the W-NiS 0.5 Se0.5 catalyst recorded in $1.0 \mathrm{M} \mathrm{KOH}$.

11 (a) HER polarization curves of $\mathrm{W}-\mathrm{NiS}_{0.5} \mathrm{Se}_{0.5}, \mathrm{NiS}_{0.5} \mathrm{Se}_{0.5}, \mathrm{NF}$, and $20 \%$ commercial Pt/C. (b)

12 Overpotentials comparison of $\mathrm{W}-\mathrm{NiS}_{0.5} \mathrm{Se}_{0.5}$ with $\mathrm{NiS}_{0.5} \mathrm{Se}_{0.5}$ and $20 \%$ commercial $\mathrm{Pt} / \mathrm{C}$ at

13 various current densities. (c) The Tafel plots of $\mathrm{W}-\mathrm{NiS}_{0.5} \mathrm{Se}_{0.5}, \mathrm{NiS}_{0.5} \mathrm{Se}_{0.5}, \mathrm{NF}$, and $20 \%$

14 commercial Pt/C. (d) TOF of the $\mathrm{W}-\mathrm{NiS}_{0.5} \mathrm{Se}_{0.5}$ compared to previous reports. (e) The normalized 
1 LSV basing on ECSA for $\mathrm{W}-\mathrm{NiS}_{0.5} \mathrm{Se}_{0.5}$ and $\mathrm{NiS}_{0.5} \mathrm{Se}_{0.5}$. (f) The long-term durability of $\mathrm{W}$ -

$2 \mathrm{NiS}_{0.5} \mathrm{Se}_{0.5}$ and $20 \%$ commercial $\mathrm{Pt} / \mathrm{C}$, the inset polarization curves were recorded before and 3 after 30,000 CV cycles.

4 Electrocatalytic OER performance. Water oxidation, with multi-electron pathways, is believed

5 to be the main limiting step for electro-catalyzing overall water splitting. As shown in Fig. 4a

6 and Supplementary Table 4, the LSV curves showed that $\mathrm{W}-\mathrm{NiS}_{0.5} \mathrm{Se}_{0.5}$ exhibited a much lower

7 overpotentials at low and high current density (171 mV@10 mA cm$~_{-2}, 239 \mathrm{mV} @ 100 \mathrm{~mA} \mathrm{~cm}{ }^{-2}$ )

8 than those of $\mathrm{IrO}_{2}$ on NF $\left(337 \mathrm{mV} @ 10 \mathrm{~mA} \mathrm{~cm}{ }^{-2}, 419 \mathrm{mV} @ 100 \mathrm{~mA} \mathrm{~cm}{ }^{-2}\right)$ and $\mathrm{NiS}_{0.5} \mathrm{Se}_{0.5}(257$

$9 \mathrm{mV} @ 10 \mathrm{~mA} \mathrm{~cm}{ }^{-2}, 331 \mathrm{mV} @ 100 \mathrm{~mA} \mathrm{~cm}{ }^{-2}$ ). Moreover, Fig. 4b and Supplementary Table 4

10 presented that the Tafel slop for $\mathrm{W}-\mathrm{NiS}_{0.5} \mathrm{Se}_{0.5}$ is $41 \mathrm{mV} \mathrm{dec}^{-1}$, which is much smaller than those

11 of $\mathrm{IrO}_{2}$ loaded on $\mathrm{NF}\left(92 \mathrm{mV} \mathrm{dec}{ }^{-1}\right)$ and $\mathrm{NiS}_{0.5} \mathrm{Se}_{0.5}\left(62 \mathrm{mV} \mathrm{dec}^{-1}\right)$, indicating a favorable OER

12 kinetic for the $\mathrm{W}-\mathrm{NiS}_{0.5} \mathrm{Se}_{0.5}$. The electrocatalytic performances of state-of-the-art OER catalysts

13 in recent literatures are summarized and presented in Fig. $4 \mathrm{c}$ and Supplementary Table 7. It is

14 obviously seen that $\mathrm{W}-\mathrm{NiS}_{0.5} \mathrm{Se}_{0.5}$ owns favorable electrocatalytic activities from overpotential

15 and Tafel slopes compared with most previously reported catalysts. The normalized LSV of W-

$16 \mathrm{NiS}_{0.5} \mathrm{Se}_{0.5}$ in Fig. $4 \mathrm{~d}$ demonstrates that the $\mathrm{W}$ dopant can greatly improve the intrinsic activity of

$17 \mathrm{NiS}_{0.5} \mathrm{Se}_{0.5}$. Compared to other OER catalysts, The $\mathrm{W}-\mathrm{NiS}_{0.5} \mathrm{Se}_{0.5}$ also exhibits the lowest $\mathrm{R}_{\mathrm{ct}}$ of

$180.65 \Omega$ (Supplementary Fig. 21 and Table 4). The TOF of W-NiS $0.5 \mathrm{Se}_{0.5}$ at $-250 \mathrm{mV}_{\mathrm{RHE}}$ were

19 calculated to be $1.85 \mathrm{~s}^{-1}$ (Supplementary Fig. 22 and Table 5), which is better than that of

$20 \mathrm{NiS}_{0.5} \mathrm{Se}_{0.5}\left(0.0011 \mathrm{~s}^{-1}\right), \mathrm{IrO}_{2}\left(0.0017 \mathrm{~s}^{-1}\right)$ and many active non-noble metal based electrocatalysts. 
1 The reason for the excellent OER activity of $\mathrm{W}-\mathrm{NiS}_{0.5} \mathrm{Se}_{0.5}$ is that $\mathrm{Ni}$ owns the lower spin state,

2 facilitating the $\mathrm{O}$ radical formation and $\mathrm{O}-\mathrm{O}$ coupling ${ }^{46}$. The detailed OER process would be 3 discussed in the DFT section below.
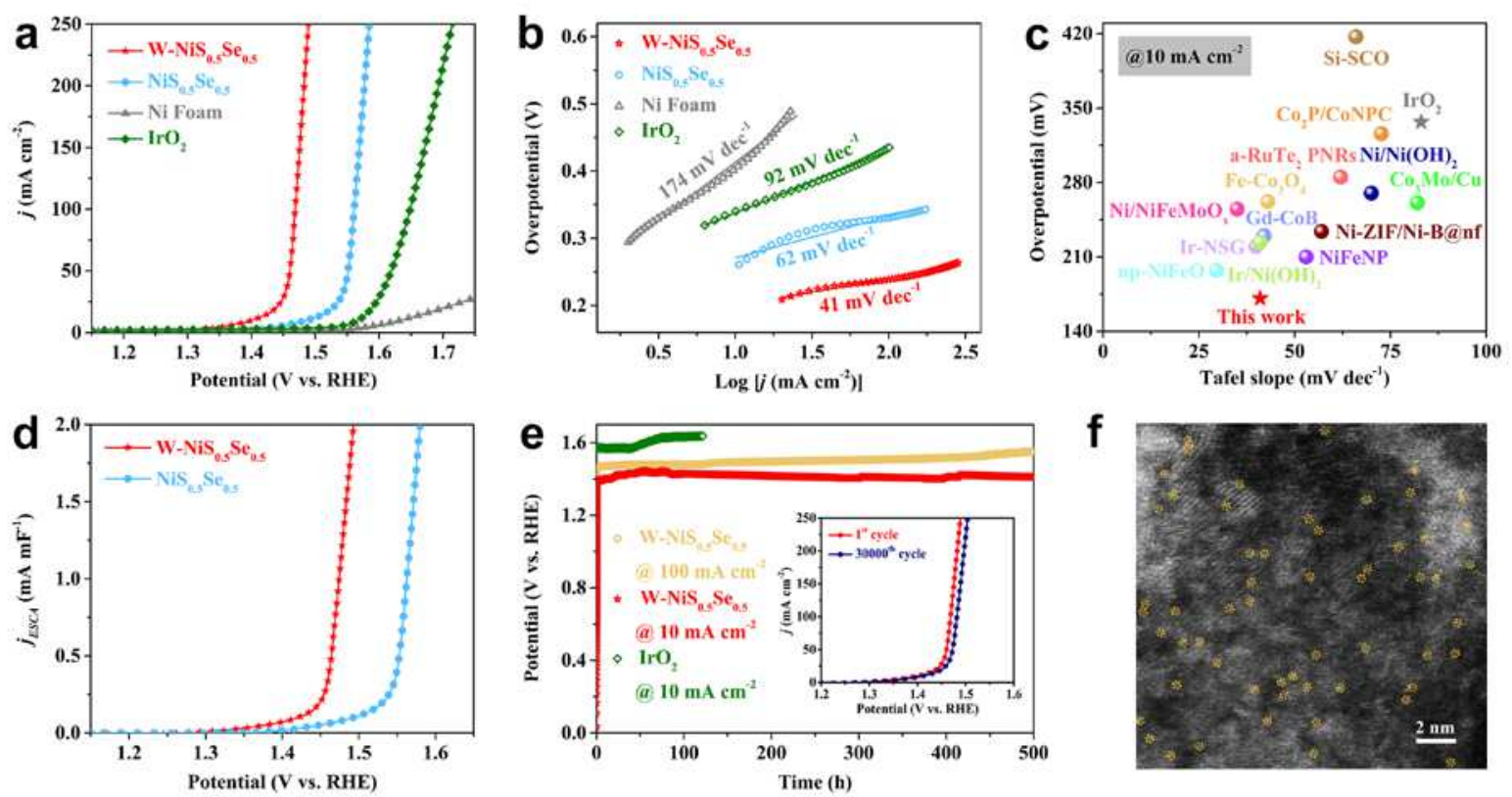

Fig. 4 Electrocatalytic OER properties of the $\mathrm{W}-\mathrm{NiS}_{0.5} \mathrm{Se}_{0.5}$ catalyst recorded in $1.0 \mathrm{M} \mathrm{KOH}$.

6 (a) OER polarization curves of $\mathrm{W}-\mathrm{NiS}_{0.5} \mathrm{Se}_{0.5}, \mathrm{NiS}_{0.5} \mathrm{Se}_{0.5}$, Ni foam, and commercial $\mathrm{IrO}_{2}$. (b) The

7 Tafel plots corresponding to (a). (c) Overpotentials and Tafel slopes of W-NiS $0.5 \mathrm{Se}_{0.5}$ at $10 \mathrm{~mA}$

$8 \mathrm{~cm}^{-2}$ compared to other representative electrocatalysts. (d) The normalized LSV basing on ECSA

9 for $\mathrm{W}-\mathrm{NiS}_{0.5} \mathrm{Se}_{0.5}$ and $\mathrm{NiS}_{0.5} \mathrm{Se}_{0.5}$. (e) The long-term durability of $\mathrm{W}-\mathrm{NiS}_{0.5} \mathrm{Se}_{0.5}$ and $\mathrm{IrO}_{2}$, the

10 inset polarization curves were recorded before and after 30,000 CV cycles. (f) The HAADF-

11 STEM image of $\mathrm{W}-\mathrm{NiS}_{0.5} \mathrm{Se}_{0.5}$ after the OER stability test.

12 In Fig. 4e, W-NiS $\mathrm{S}_{0.5} \mathrm{Se}_{0.5}$ shows extreme stability after operating OER at 10 and $100 \mathrm{~mA} \mathrm{~cm}{ }^{-2}$

13 for $500 \mathrm{~h}$. On the other hand, $\mathrm{W}-\mathrm{NiS}_{0.5} \mathrm{Se}_{0.5}$ also displays a negligible degradation after testing

$1430,000 \mathrm{CV}$ cycles (inset in Fig. 4e), further manifesting its exceptional stability during the OER 
1 process. The post-measurements of XRD, XPS, EDX, TEM, and STEM for $\mathrm{W}-\mathrm{NiS}_{0.5} \mathrm{Se}_{0.5}$

2 exhibit that (Fig. 4f, Supplementary Figs. 23-25 and Table 6) the doped W single-atom remains

3 the original morphology and composition in $\mathrm{NiS}_{0.5} \mathrm{Se}_{0.5}$, signifying the outstanding structural

4 stability. The high durability of the $\mathrm{W}-\mathrm{NiS}_{0.5} \mathrm{Se}_{0.5}$ is mainly due to the unique structure of the $\mathrm{W}$ -

$5 \mathrm{~S} /$ Se moiety, leading to strong interaction between the monodispersed $\mathrm{W}$ atoms and the substrate.

6 Electrocatalytic performance for overall water splitting. As shown in Fig. $5 \mathrm{a}, \mathrm{W}-\mathrm{NiS}_{0.5} \mathrm{Se}_{0.5}$

7 owns higher HER and OER activity than $\mathrm{Pt} / \mathrm{C}+\mathrm{IrO}_{2}$, thus it is expected to assemble a two-

8 electrode water splitting system by using it as cathode and anode. The W-NiS $\mathrm{S}_{0.5} \mathrm{Se}_{0.5} \| \mathrm{W}-$

$9 \mathrm{NiS}_{0.5} \mathrm{Se}_{0.5}$ system features lower potentials of 1.44 and $1.55 \mathrm{~V}$ to achieve 10 and $100 \mathrm{~mA} \mathrm{~cm}^{-2}$,

10 respectively. The water-splitting property of $\mathrm{W}-\mathrm{NiS}_{0.5} \mathrm{Se}_{0.5} \| \mathrm{W}-\mathrm{NiS} \mathrm{S}_{0.5} \mathrm{Se}_{0.5}$ is much better than

11 those of $\mathrm{NiS}_{0.5} \mathrm{Se}_{0.5} \| \mathrm{NiS}_{0.5} \mathrm{Se}_{0.5}$ and commercial $\mathrm{IrO}_{2} \| \mathrm{Pt} / \mathrm{C}$ (Fig. 5b) and even surpasses the most

12 reported electrocatalysts (Supplementary Table 8). The amazing stability of $\mathrm{W}-\mathrm{NiS}_{0.5} \mathrm{Se}_{0.5} \| \mathrm{W}-$

$13 \mathrm{NiS}_{0.5} \mathrm{Se}_{0.5}$ can be observed in Fig. $5 \mathrm{c}$, measured at $10 \mathrm{~mA} \mathrm{~cm}{ }^{-2}$ or even at $100 \mathrm{~mA} \mathrm{~cm}{ }^{-2}$ for $500 \mathrm{~h}$,

14 which operating time is much longer than commercial $\mathrm{IrO}_{2} \| \mathrm{Pt} / \mathrm{C}$. Moreover, the slight

15 degradation of $\mathrm{W}-\mathrm{NiS}_{0.5} \mathrm{Se}_{0.5} \| \mathrm{W}-\mathrm{NiS}_{0.5} \mathrm{Se}_{0.5}$ testing for 30,000 CV cycles (inset in Fig. $5 \mathrm{c}$ )

16 confirms its excellent stability again. The experimental evolved $\mathrm{H}_{2}$ and $\mathrm{O}_{2}$ amounts of W-

$17 \mathrm{NiS}_{0.5} \mathrm{Se}_{0.5} \| \mathrm{W}-\mathrm{NiS}_{0.5} \mathrm{Se}_{0.5}$ system are matched well with the theoretical values, suggesting its

18 Faradaic efficiency close to $100 \%$ (Supplementary Fig. 26). What's more, the W-NiS $\mathrm{N}_{0.5} \mathrm{Se}_{0.5} \| \mathrm{W}$ -

$19 \mathrm{NiS}_{0.5} \mathrm{Se}_{0.5}$ system can drive water splitting by a commercially available alkaline battery (1.5 V) 
1 and observe clear $\mathrm{H}_{2}$ and $\mathrm{O}_{2}$ bubbles (Fig. 5d), demonstrating its good overall water splitting 2 performances.
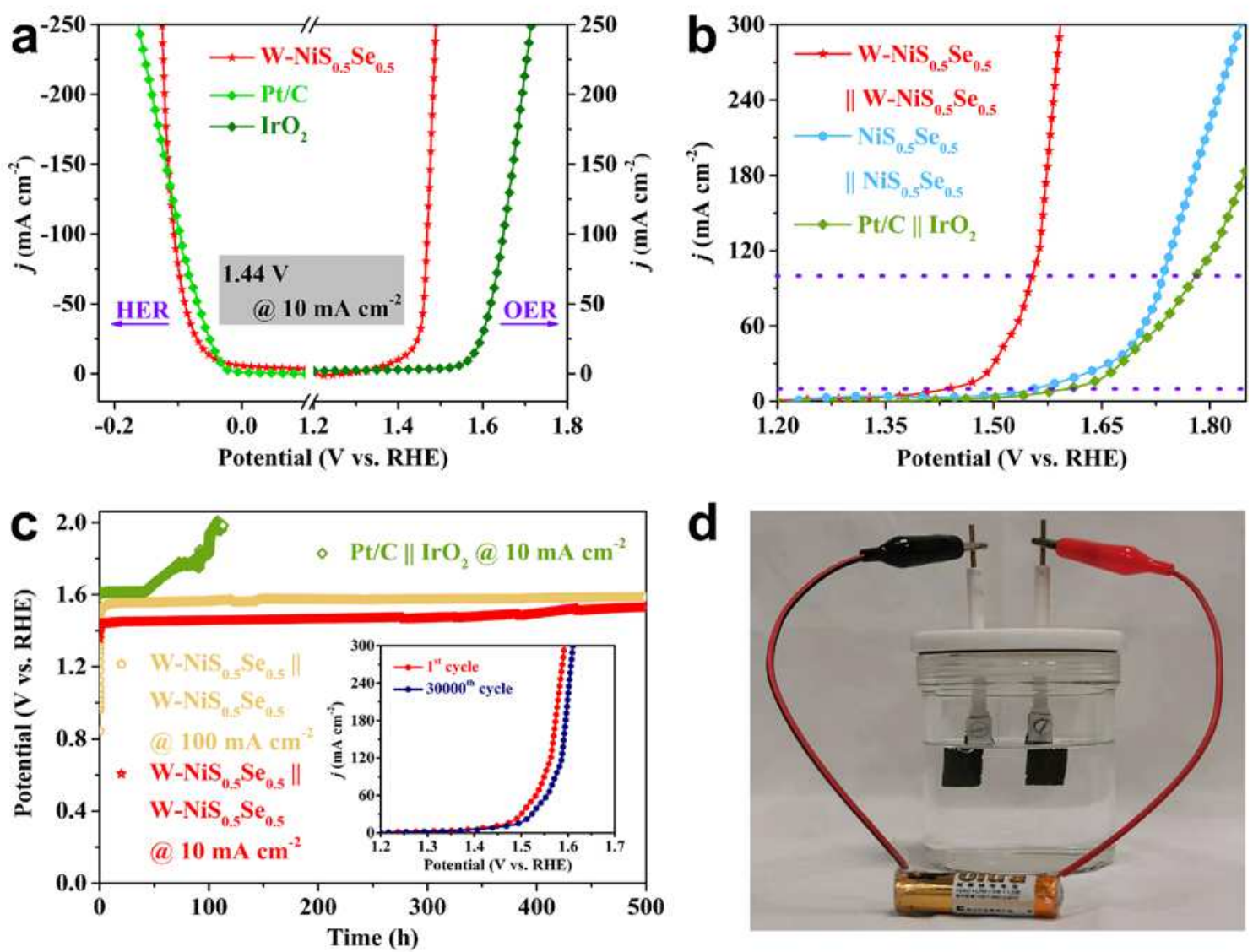

KOH. (a) HER and OER polarization curves of $\mathrm{W}-\mathrm{NiS}_{0.5} \mathrm{Se}_{0.5}, \mathrm{Pt} / \mathrm{C}$, and $\mathrm{IrO}_{2}$. (b) The polarization curves of $\mathrm{W}-\mathrm{NiS}_{0.5} \mathrm{Se}_{0.5}\left\|\mathrm{~W}-\mathrm{NiS}_{0.5} \mathrm{Se}_{0.5}, \mathrm{NiS}_{0.5} \mathrm{Se}_{0.5}\right\| \mathrm{NiS}_{0.5} \mathrm{Se}_{0.5}$, and $\mathrm{Pt} / \mathrm{C} \| \mathrm{IrO}_{2}$.

7 The long-term durability of $\mathrm{W}-\mathrm{NiS}_{0.5} \mathrm{Se}_{0.5} \| \mathrm{W}-\mathrm{NiS}_{0.5} \mathrm{Se}_{0.5}$ and $\mathrm{Pt} / \mathrm{C} \| \mathrm{IrO}_{2}$ for water splitting, the

8 inset polarization curves were recorded before and after 30,000 CV cycles. (d) The gas evolution

9 photographic image of $\mathrm{W}-\mathrm{NiS}_{0.5} \mathrm{Se}_{0.5} \| \mathrm{W}-\mathrm{NiS}_{0.5} \mathrm{Se}_{0.5}$ powered by a commercial $1.5 \mathrm{~V}$ AA battery.

10 To prove the universality, we synthesized the W-NiS and W-NiSe nanosheet@NiS and NiSe 11 nanorods and which also show higher HER/OER and overall water splitting activity than those of 
1 NiS and NiSe (Supplementary Figs. 27-29). Consequently, this one-step facile method can be

2 considered as a mild-efficient and low-cost route to synthesize the W single-atom doped TCMs

3 materials. In addition, the prepared $\mathrm{W}-\mathrm{NiS}_{0.5} \mathrm{Se}_{0.5}$ can be believed to be a promising candidate to

4 replace precious metals, which also can serve as the next-generation catalysts to electro-catalyze

5 water splitting under alkaline conditions.

6 First-principles calculations. To further uncover the modulation principle of $\mathrm{W}-\mathrm{NiS}_{0.5} \mathrm{Se}_{0.5}$ for

7 HER/OER catalytic activities at the atomic scale, density function theory (DFT) was performed.

8 The optimized structures in $\mathrm{W}-\mathrm{NiS}_{0.5} \mathrm{Se}_{0.5}$ and $\mathrm{NiS}_{0.5} \mathrm{Se}_{0.5}$ are displayed in Supplementary Figs.

9 30,31. Fig. 6a shows the projected density of states (PDOS) of $\mathrm{W}-\mathrm{NiS}_{0.5} \mathrm{Se}_{0.5}$ and $\mathrm{NiS}_{0.5} \mathrm{Se}_{0.5}$.

10 New hybridized electronic states have emerged as $\mathrm{W}$ single-atom doping into $\mathrm{NiS}_{0.5} \mathrm{Se}_{0.5}$, which

11 is mainly caused by the hybridization between $\mathrm{W}$ and S/Se atoms. Compared with the PDOS of

$12 \mathrm{NiS}_{0.5} \mathrm{Se}_{0.5}$, specifically, a change that occurs around the Fermi level in $\mathrm{W}-\mathrm{NiS}_{0.5} \mathrm{Se}_{0.5}$ and is

13 mostly induced by the Ni $2 \mathrm{p}$ orbitals. The results demonstrate that the $\mathrm{W}$ single-atom dopant can

14 efficiently optimize the electron state of $\mathrm{Ni}$ atoms in $\mathrm{NiS}_{0.5} \mathrm{Se}_{0.5}$ and finally improve its catalytic

15 activity. Generally, the adsorption Gibbs free energy $\left(\Delta \mathrm{G}^{*}\right)$ on a catalyst surface is a well-known

16 descriptor for investigating the catalytic activity. As shown in Supplementary Figs. 32,33, the

17 bond length of $\mathrm{H}-\mathrm{Ni}$ of $\mathrm{W}-\mathrm{NiS}_{0.5} \mathrm{Se}_{0.5}$ was estimated to be $1.687 \AA$, the bond length of $\mathrm{H}-\mathrm{W}$ of

18 W-NiS $\mathrm{S}_{0.5} \mathrm{Se}_{0.5}$ was estimated to be $1.6826 \AA$, longer than the $1.6059 \AA$ of $\mathrm{NiS}_{0.5} \mathrm{Se}_{0.5}$, which

19 indicates the relatively weak $\mathrm{H}-\mathrm{Ni} / \mathrm{H}-\mathrm{W}$ bonds on the $\mathrm{W}-\mathrm{NiS}_{0.5} \mathrm{Se}_{0.5}$ and is, in turn, conducive to

20 the formation of $\mathrm{H}-\mathrm{H}$ by the recombination of two adjacently adsorbed $\mathrm{H}$. As shown in Fig. 6b, 
1 the $\mathrm{NiS}_{0.5} \mathrm{Se}_{0.5}$ has a large energy barrier on $\mathrm{Ni}$ site, indicating a sluggish process. In contrast, the

2 calculated hydrogen adsorption free energy of $\mathrm{W}-\mathrm{NiS}_{0.5} \mathrm{Se}_{0.5}$ shows a dramatically decreased

$3 \Delta \mathrm{G}_{\mathrm{H}^{*}}$ of on $\mathrm{Ni}$ site and low $\Delta \mathrm{G}_{\mathrm{H}^{*}}$ of on $\mathrm{W}$ site, suggesting an accelerated

4 adsorption/desorption of $\mathrm{H}$ after the introduction of atomic-level $\mathrm{W}$. These results indicate that

5 the Ni site and $\mathrm{W}$ site are the active site for HER on $\mathrm{W}-\mathrm{NiS}_{0.5} \mathrm{Se}_{0.5}$. To further understand the

6 catalytic nature of $\mathrm{W}-\mathrm{NiS}_{0.5} \mathrm{Se}_{0.5}$, we correlated the calculated $\Delta \mathrm{G}_{\mathrm{H}^{*}}$ with the exchange current

7 density (jo, Supplemental Fig. 34) from the Tafel diagram and obtained the volcano diagram (Fig.

8 4c). It can be seen that the activity of the $\mathrm{W}-\mathrm{NiS}_{0.5} \mathrm{Se}_{0.5}$ evaluated by $\Delta \mathrm{G}_{\mathrm{H}^{*}}$ and $j_{0}$ in alkaline

9 solution is higher than that of the common noble and nonnoble metals in alkaline solution ${ }^{55,56}$.

10 Remarkably, the activity of the $\mathrm{W}-\mathrm{NiS}_{0.5} \mathrm{Se}_{0.5}$ even surpasses the state-of-the-art $\mathrm{Pt} / \mathrm{C}$ catalysts in

11 alkaline solution. Moreover, we researched the energetic pathway during the OER process in W-

$12 \mathrm{NiS}_{0.5} \mathrm{Se}_{0.5}$ and $\mathrm{NiS}_{0.5} \mathrm{Se}_{0.5}$, and the corresponding adsorption sites are shown in Figs. 6d and

13 Supplementary Fig. 35. The typical OER mechanism in $\mathrm{W}-\mathrm{NiS}_{0.5} \mathrm{Se}_{0.5}$ is illustrated in Fig. 6d. In

14 detail, the $* \mathrm{OH}$ species first form on the $\mathrm{Ni}$ sites and then donate one proton to the system.

15 Secondly, a single oxygen atom adsorbs on the Ni sites and reacts with water via nucleophilic

16 attack, and then occurring deprotonation to generate $* \mathrm{OOH}$. The $* \mathrm{OOH}$ has been formed in the

17 third step and always acts as the potential determining step during the OER process. Finally, the

18 proton-coupled electron transfer would result in the release of $\mathrm{O}_{2}{ }^{57}$. The $\Delta \mathrm{G}^{*}$ of W-NiS ${ }_{0.5} \mathrm{Se}_{0.5}$

19 and $\mathrm{NiS}_{0.5} \mathrm{Se}_{0.5}$ for OER is illustrated in Supplementary Fig. 36. At $\mathrm{U}=0 \mathrm{~V}$, the transformation

20 of $[* \mathrm{O}]$ to $[* \mathrm{OOH}]$ needs to overcome a larger barrier, suggesting the determining step for $\mathrm{W}$ - 
$1 \mathrm{NiS}_{0.5} \mathrm{Se}_{0.5}$ and $\mathrm{NiS}_{0.5} \mathrm{Se}_{0.5}$ both is the formation of $\left[{ }^{*} \mathrm{OOH}\right]$. The $\mathrm{W}$ atomic site incorporated

$2 \mathrm{NiS}_{0.5} \mathrm{Se}_{0.5}$ lowers the barrier $(1.41 \mathrm{eV})$ than that of $1.59 \mathrm{eV}$ in $\mathrm{NiS}_{0.5} \mathrm{Se}_{0.5}$.
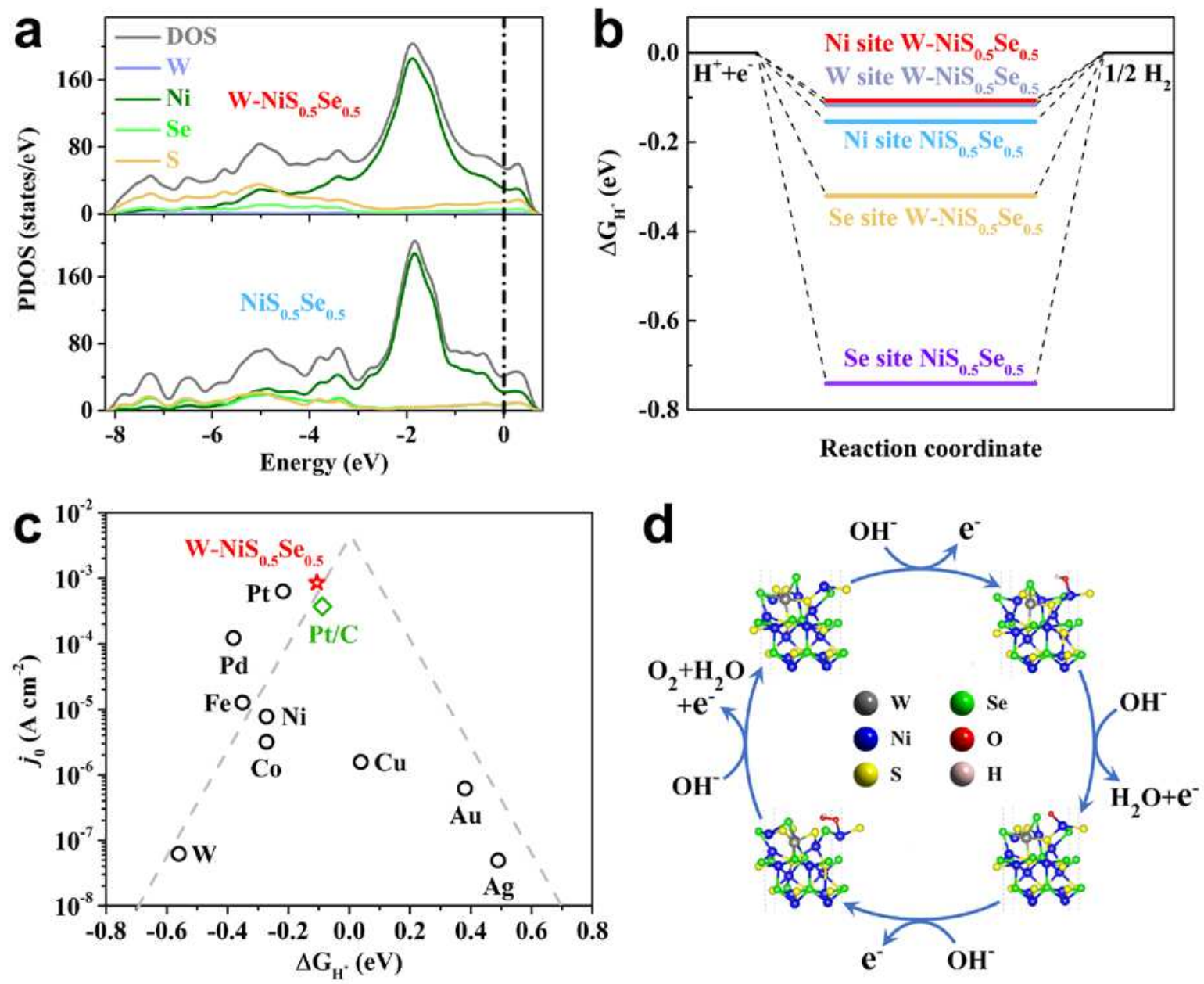

4 Fig. 6 Optimized geometry of adsorption structure (a) Calculated PDOS of $\mathrm{W}-\mathrm{NiS}_{0.5} \mathrm{Se}_{0.5}$ and

$5 \mathrm{NiS}_{0.5} \mathrm{Se}_{0.5}$. (b) The calculated $\Delta \mathrm{G}_{\mathrm{H}^{*}}$ of different $\mathrm{H}^{*}$ adsorption site on $\mathrm{W}-\mathrm{NiS}_{0.5} \mathrm{Se}_{0.5}$ and

$6 \mathrm{NiS}_{0.5} \mathrm{Se}_{0.5}$, respectively. (c) The proposed possible process of $\mathrm{W}-\mathrm{NiS}_{0.5} \mathrm{Se}_{0.5}$ on OER process. (d)

7 Volcano plots of $j_{0}$ measured in alkaline solution as a function of the $\Delta \mathrm{G}_{\mathrm{H}^{*}}$ for pure metals ${ }^{55,56}$

8 (black circles) and the state-of-the-art $\mathrm{Pt} / \mathrm{C}$ (green diamond), as well as the $\mathrm{W}-\mathrm{NiS}_{0.5} \mathrm{Se}_{0.5}$ (red

9 star). The dashed lines are used to guide the eye. 


\section{Discussion}

2 In summary, we have demonstrated that $\mathrm{W}-\mathrm{NiS}_{0.5} \mathrm{Se}_{0.5}$, synthesized by a simple universality 3 one-step approach, is a highly active and robust HER/OER electrocatalyst in alkaline media. The

4 HER/OER properties of $\mathrm{W}-\mathrm{NiS}_{0.5} \mathrm{Se}_{0.5}$ outperform commercial $\mathrm{Pt} / \mathrm{C}, \mathrm{IrO}_{2}$, and other previously 5 reported electrocatalysts. The replacement of $\mathrm{Ni}$ by $\mathrm{W}$ will provide some additional adsorption

6 sites on the $\mathrm{W}-\mathrm{NiS}_{0.5} \mathrm{Se}_{0.5}$. The low-spin of $\mathrm{W}$ single-atom would gear toward tuning the

7 delocalization of $\mathrm{Ni}$ spin states, which increases the $\mathrm{Ni} 2 \mathrm{p}$ electronic states, optimized $\mathrm{H}^{*}$ 8 adsorption kinetics, significantly reducing the energy barrier for the rate-determining step $\left(\mathrm{O}^{*}\right.$ to

$\left.9 \mathrm{OOH}^{*}\right)$. The superior catalytic performance of the $\mathrm{W}-\mathrm{Ni} \mathrm{S}_{0.5} \mathrm{Se}_{0.5}$ catalyst highlights the 10 importance of atomic-level engineering strategy for electronic structure tuning of electrocatalysts 11 to effectively manipulate their catalytic properties.

\section{Methods}

14 Synthesis of $\mathbf{W}-\mathbf{N i S}_{\mathbf{0 . 5}} \mathrm{Se}_{\mathbf{0 . 5}}$. In a typical synthesis of the $\mathrm{NiS}_{0.5} \mathrm{Se}_{0.5}$, to remove the nickel oxides on the NF

15 surface, the $\mathrm{NF}$ was soaked in $1 \mathrm{M} \mathrm{HCl}$ solution firstly, then washed with deionized water, acetone and ethanol

16 in turns. The NF was dried in a vacuum oven to avoid reoxidation. In detail, $0.288 \mathrm{~g}$ selenium powder was

17 firstly dissolved in $6 \mathrm{ml}$ hydrazine hydrate with stirring for $20 \mathrm{~min}$. Then $0.278 \mathrm{~g}$ thiourea, $0.4 \mathrm{~g}$ ammonium

18 fluoride, $15 \mathrm{ml}$ ethanol and $9 \mathrm{ml}$ water were added. After stirring for $30 \mathrm{~min}, 0.835 \mathrm{~g}$ tungsten trioxide was

19 added. After stirring for another $30 \mathrm{~min}$, the obtained solution with a dried NF $\left(1 \times 2.5 \mathrm{~cm}^{2}\right)$ was put into a 50

$20 \mathrm{ml}$ Teflon-lined stainless autoclave to process the solvothermal reaction at $220{ }^{\circ} \mathrm{C}$ for $24 \mathrm{~h}$. After cooling to the

21 room temperature, the obtained $\mathrm{W}-\mathrm{NiS}_{0.5} \mathrm{Se}_{0.5}$ was washed with deionized water for three times then frozen

22 drying. 
1 Materials characterizations. The crystal structure of the samples was analyzed by the powder XRD (Bruker

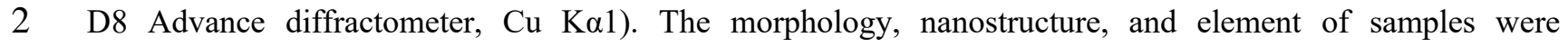

3 investigated by SEM (Hitachi S4800, $30 \mathrm{kV}$ ) equipped with EDX (Genesis XM2), TEM (JEOL JEM-2100F,

$4200 \mathrm{kV}$ ) and HAADF-STEM (JEOL JEM-ARM200F). ICP-mass spectrometry (ICP-MS) was utilized to

5 characterize the composition of the nanocrystals. The chemical valence state and the surface atomic ratio were

6 measured by XPS (Perkin Elmer PHI 1600 ECSA system). XAFS experiments were performed at the 1W1B

7 beamline of the National University of Singapore Synchrotron Radiation Facility. The storage ring runs at 2.0

$8 \mathrm{GeV}$ with a maximum electron current of about $450 \mathrm{~mA}$. The energy range of the incident $\mathrm{X}$-ray is tunable

9 from 4 to $25 \mathrm{keV}$ by fix-exit $\mathrm{Si}$ (111) double crystal monochromator. The absorption edge of standard metal

10 foils was used to calibrate the X-ray energy. Samples were ground into fine powers and then pressed into thin

11 disks of $10 \mathrm{~mm}$ in diameter. $\mathrm{W} \mathrm{L}_{3}$-edge and Ni K-edge XANES/EXAFS spectra were collected at room

12 temperature in transmission mode. The magnetic measurements were carried out with a MPMS SQUID

13 magnetometer.

14 Electrochemical test. All electrochemical investigations were conducted at room-temperature. The HER and

15 OER electrocatalytic activity were tested in $1 \mathrm{M} \mathrm{KOH}$ by a three-electrode configuration on a CHI660B

16 workstation, and the overall water splitting was tested by a two-electrode system. As a 3D electrode, the as-

17 obtained sample was used as the working electrodes $(1 \mathrm{~cm} \times 1 \mathrm{~cm})$, and the counter electrode was a graphite

18 rod. While a saturated calomel electrode (SCE) was used as the reference electrode. All the potentials were

19 calibrated to the reversible hydrogen electrode (RHE) on the basis of the Nernst equation. The working

20 electrodes were activated by using the CV test for several times at a scan rate of $50 \mathrm{mV} \mathrm{s}^{-1}$ before measuring 
the CV and LSV. LSV was carried out at a scan rate of $5 \mathrm{mV} \mathrm{s}^{-1}$. All polarization curves were corrected with the IR in this work unless noted otherwise. Tafel plots were obtained from the polarization curves

3 (overpotential $(\eta)$ versus the logarithm of current density $(\log |J|)$ ). EIS were performed from $100 \mathrm{kHz}$ to 0.01

$4 \mathrm{~Hz}$ under an AC voltage $(10 \mathrm{mV})$ at $0.6 \mathrm{~V}$ and $-1.2 \mathrm{~V}$ vs. SCE for OER and HER, respectively. Accelerated

5 durability tests of catalysts were performed by continuous potential cycling between $0 \sim 0.5 \mathrm{~V}$ and $-0.9 \sim-1.2$

6 V vs. SCE for OER and HER at a scan rate of $100 \mathrm{mV} \mathrm{s}^{-1}$ for 30,000 cycles. The chronopotentiometry tests

7 were performed for $500 \mathrm{~h}$ at a constant current density of 10 and $100 \mathrm{~mA} \mathrm{~cm}{ }^{-2}$. The electrochemical $\mathrm{C}_{\mathrm{dl}}$ was

8 measured by $\mathrm{CV}$ method. The potential was swept at 5, 10, 15, 25, 50,100, 150, and $200 \mathrm{mV} \mathrm{s}^{-1}$ from 0.37 to

$9 \quad 0.47 \mathrm{~V}$ versus RHE, where no faradic current was observed. The halves of the positive and negative current

10 density at the center of the scanning range (i.e., $0.42 \mathrm{~V}$ ) with different scan rates were plotted, and the slopes

11 represent the double-layer capacitance. The overall water splitting tests were conducted by a two-electrode

12 system and the catalysts loaded on NF (mass loading: $2.4 \mathrm{mg} \mathrm{cm}^{-2}$ ). Polarization curves were obtained at a

13 scan rate of $5 \mathrm{mV} \mathrm{s}^{-1}$. For the working electrodes containing commercial $20 \mathrm{wt} . \% \mathrm{Pt} / \mathrm{C}$ or $\mathrm{IrO}_{2}$ catalyst, $10 \mathrm{mg}$

$14 \mathrm{Pt} / \mathrm{C}$ or $\mathrm{IrO}_{2}$ and $35 \mu \mathrm{l}$ of $5 \mathrm{wt} . \%$ Nafion solution were dispersed in $965 \mu \mathrm{l}$ isopropanol by sonication to form a

15 homogeneous ink. The as-prepared catalyst ink $(240 \mu \mathrm{l})$ was dropped on the surface of the NF, yielding an

16 approximate catalyst loading of $2.4 \mathrm{mg} \mathrm{cm}^{-2}$.

17 Computational details. The surfaces of NiS (101), $\mathrm{NiS}_{0.5} \mathrm{Se}_{0.5}$ (101), NiS-NiS $\mathrm{N}_{0.5} \mathrm{Se}_{0.5}$ (101), W-NiS (101), W-

$18 \mathrm{NiS}_{0.5} \mathrm{Se}_{0.5}(101)$ and $\mathrm{W}-\mathrm{NiS}-\mathrm{NiS}_{0.5} \mathrm{Se}_{0.5}(101)$ were built, where the vacuum space along the $\mathrm{z}$ direction is set

19 to be $20 \AA$, which is enough to avoid interaction between the two neighboring images. Then the $\mathrm{H}, \mathrm{OH}, \mathrm{O}$ and

20 OOH have been loading on the surface. The bottom three atomic layers were fixed, the top three atomic layers 
1 were relaxed adequately. The first principles calculations in the framework of density functional theory were

2 carried out based on the Cambridge Sequential Total Energy Package known as CASTEP ${ }^{58}$. The exchange-

3 correlation functional under the generalized gradient approximation (GGA) ${ }^{59}$ with norm-conserving

4 pseudopotentials and Perdew-Burke-Ernzerhof functional was adopted to describe the electron-electron

5 interaction ${ }^{60}$. An energy cutoff of $750 \mathrm{eV}$ was used and a k-point sampling set of $5 \times 5 \times 1$ were tested to be

6 converged. A force tolerance of $0.01 \mathrm{eV}^{-1}$, energy tolerance of $5.0 \times 10^{-7} \mathrm{eV}$ per atom and maximum

7 displacement of $5.0 \times 10^{-4} \AA$ A were considered.

8 The adsorption energy of $\mathrm{A}=\mathrm{H}, \mathrm{OH}, \mathrm{O}$ and $\mathrm{OOH}$ were calculated by ${ }^{61}$ :

$$
\Delta E_{A}=E_{*_{A}}-E_{*}-E_{A}
$$

10 where $E_{*_{A}}, E_{*}$ and $E_{A}$ denote the energy of adsorbed system, clear surface and a group. The electrochemical

11 model of OER can be divided into four one-electron reactions ${ }^{62}$ :

$$
* \mathrm{OOH}+3\left(\mathrm{H}^{+}+\mathrm{e}^{-}\right) \rightarrow \mathrm{O}_{2}+*+4\left(\mathrm{H}^{+}+\mathrm{e}^{-}\right)
$$

16 According to the method presented by Nørskov, the Gibbs free energy diagrams were estimated by the 17 following equation, 
where $\triangle E$ is the energy change between the reactant and product obtained from DFT calculations; $\triangle Z P E$ is the

3 temperature with unit $\mathrm{K}$. In here, $T=300 \mathrm{~K}$ was considered.

4 The formation energy $E_{\mathrm{f}}$ is:

$$
E_{\mathrm{f}}=\left(E_{\mathrm{sys}}-\mu_{\mathrm{ni}} * \mathrm{~N}_{\mathrm{Ni}}-\mu_{\mathrm{W}} * \mathrm{~N}_{\mathrm{W}}-\mu_{\mathrm{S}} * \mathrm{~N}_{\mathrm{S}}-\mu_{\mathrm{Se}} * \mathrm{~N}_{\mathrm{Se}}\right) / \mathrm{N}
$$

where $E_{\mathrm{sys}}$ and $\mathrm{N}$ denote the total energy and number of atoms in systems, $\mu_{\mathrm{Ni}}, \mu_{\mathrm{W}}, \mu_{\mathrm{S}}$ and $\mu_{\mathrm{Se}}$ are the chemical

7 potentials of $\mathrm{Ni}, \mathrm{W}, \mathrm{S}$ and $\mathrm{Se}$ atoms in the pristine bulk, $\mathrm{N}_{\mathrm{Ni}}, \mathrm{N}_{\mathrm{W}}, \mathrm{N}_{\mathrm{S}}$ and $\mathrm{N}_{\mathrm{Se}}$ are the number of $\mathrm{Ni}, \mathrm{W}, \mathrm{S}$ and 8 Se atoms in systems.

\section{References}

11 1. Zang, Y. et al. Tuning orbital orientation endows molybdenum disulfide with exceptional 12 alkaline hydrogen evolution capability. Nat. Commun. 10, 1-8, (2019).

13 2. Li, F. et al. Mechanochemically Assisted Synthesis of a Ru Catalyst for Hydrogen Evolution 14 with Performance Superior to Pt in Both Acidic and Alkaline Media. Adv. Mater. 30, $15 \quad 1803676,(2018)$.

16 3. Wei, C. et al. Approaches for measuring the surface areas of metal oxide electrocatalysts for 17 determining their intrinsic electrocatalytic activity. Chem. Soc. Rev. 48, 2518-2534 (2019).

18 4. Dresselhaus, M. S. \& Thomas, I. L. Alternative energy technologies. Nature 414, 332-337 (2001). 
16 . Chu, S. \& Majumdar, A. Opportunities and challenges for a sustainable energy future.

$2 \quad$ Nature 488, 294-303 (2012).

3 7. Tang, T. et al. Electronic and Morphological Dual Modulation of Cobalt Carbonate

$4 \quad$ Hydroxides by Mn Doping toward Highly Efficient and Stable Bifunctional Electrocatalysts

5 for Overall Water Splitting. J. Am. Chem. Soc. 139, 8320-8328 (2017).

6 8. Yu, F. et al. High-performance bifunctional porous non-noble metal phosphide catalyst for

7 overall water splitting. Nat. Commun. 9, 1-9 (2018).

8 9. Du, N. et al. Trimetallic TriStar Nanostructures: Tuning Electronic and Surface Structures

9 for Enhanced Electrocatalytic Hydrogen Evolution. Adv. Mater. 28, 2077-2084 (2016).

10 10. Bai, S. et al. Surface Polarization Matters: Enhancing the Hydrogen-Evolution Reaction by

11 Shrinking Pt Shells in Pt-Pd-Graphene Stack Structures. Angew. Chemie. Int. Ed. 53, 12120-

$1212124(2014)$.

13 11. Seitz, L. C. et al. A highly active and stable $\mathrm{IrO}_{\mathrm{x}} / \mathrm{SrIrO}_{3}$ catalyst for the oxygen evolution

14 reaction, Science. $\mathbf{3 5 3}, 1011$ (2016).

15 12. Anantharaj, S. et al. Recent Trends and Perspectives in Electrochemical Water Splitting with 16 an Emphasis on Sulfide, Selenide, and Phosphide Catalysts of Fe, Co, and Ni: A Review.

17 ACS Catal. 6, 8069-8097 (2016).

18 13. Zhao, G., Li, P., Cheng, N., Dou, S. X. \& Sun, W. An $\operatorname{Ir} / \mathrm{Ni}(\mathrm{OH})_{2}$ Heterostructured

19 Electrocatalyst for the Oxygen Evolution Reaction: Breaking the Scaling Relation,

20 Stabilizing Iridium(V), and Beyond. Adv. Mater. 32, 1-9 (2020). 
1 14. Jiang, K. et al. Dynamic active-site generation of atomic iridium stabilized on nanoporous

2 metal phosphides for water oxidation. Nat. Commun. 11, 1-9 (2020).

3 15. Li, H. et al. Systematic design of superaerophobic nanotube-array electrode comprised of

4 transition-metal sulfides for overall water splitting. Nat. Commun. 9, 1-12 (2018).

5 16. Yang, J. et al. $\mathrm{Fe}_{3} \mathrm{O}_{4}$-Decorated $\mathrm{Co}_{9} \mathrm{~S}_{8}$ Nanoparticles In Situ Grown on Reduced Graphene

6 Oxide: A New and Efficient Electrocatalyst for Oxygen Evolution Reaction. Adv. Funct.

$7 \quad$ Mater. 26, 4712 (2016).

8 17. Xiong, Q. et al. Cobalt Covalent Doping in MoS2 to Induce Bifunctionality of Overall Water

9 Splitting. Adv. Mater. 30, 1-7 (2018).

10 18. Sun, Y. et al. Strong Electronic Interaction in Dual-Cation-Incorporated $\mathrm{NiSe}_{2}$ Nanosheets

11 with Lattice Distortion for Highly Efficient Overall Water Splitting. Adv. Mater. 30, 1-7

$12 \quad(2018)$.

13 19. Liu, Y. et al. Heterogeneous Spin States in Ultrathin Nanosheets Induce Subtle Lattice

14 Distortion to Trigger Efficient Hydrogen Evolution. J. Am. Chem. Soc. 138, 5087-5092 15 (2016).

16 20. Xie, J. et al. Controllable disorder engineering in oxygen-incorporated $\mathrm{MoS}_{2}$ ultrathin 17 nanosheets for efficient hydrogen evolution. J. Am. Chem. Soc. 135, 17881-17888 (2013).

18 21. Xie, J. et al. Defect-rich $\mathrm{MoS}_{2}$ ultrathin nanosheets with additional active edge sites for 19 enhanced electrocatalytic hydrogen evolution. Adv. Mater. 25, 5807-5813 (2013).

20 22. Wang, D. Y. et al. Highly active and stable hybrid catalyst of cobalt-doped $\mathrm{FeS}_{2}$ nanosheets- 
carbon nanotubes for hydrogen evolution reaction. J. Am. Chem. Soc. 137, 1587-1592 (2015).

23. Deng, J. et al. Triggering the electrocatalytic hydrogen evolution activity of the inert two-

4 dimensional $\mathrm{MoS}_{2}$ surface via single-atom metal doping. Energy Environ. Sci. 8, 1594-1601 (2015).

24. Pattengale, B. et al. Dynamic evolution and reversibility of single-atom Ni(II) active site in 1T-MoS 2 electrocatalysts for hydrogen evolution. Nat. Commun. 11, 1-9 (2020).

8 25. Jiang, K. et al. Single platinum atoms embedded in nanoporous cobalt selenide as 9 electrocatalyst for accelerating hydrogen evolution reaction. Nat. Commun. 10, 1-9 (2019).

10 26. Peng, Y., Lu, B. \& Chen, S. Carbon-Supported Single Atom Catalysts for Electrochemical 11 Energy Conversion and Storage. Adv. Mater. 30, 1-25 (2018).

12 27. Zhang, J. et al. Cation vacancy stabilization of single-atomic-site $\mathrm{Pt}_{1} / \mathrm{Ni}(\mathrm{OH})_{\mathrm{x}}$ catalyst for 13 diboration of alkynes and alkenes. Nat. Commun. 9, 1-8 (2018).

14 28. Zhang, M. et al. Metal (Hydr)oxides@ Polymer Core-Shell Strategy to Metal Single-Atom 15 Materials. J. Am. Chem. Soc. 139, 10976-10979 (2017).

16 29. Chen, W. et al. Single Tungsten Atoms Supported on MOF-Derived N-Doped Carbon for 17 Robust Electrochemical Hydrogen Evolution. Adv. Mater. 30, 1-6 (2018).

18 30. Chen, Y. et al. Single-Atom Catalysts: Synthetic Strategies and Electrochemical Applications. Joule 2, 1242-1264 (2018). 
1 31. Ivanov, I. P. \& Karlovets, D. V. Polarization radiation of vortex electrons with large orbital 2 angular momentum. Phys. Rev. A - At. Mol. Opt. Phys. 88, 1-15 (2013).

3 32. Chen, Z. et al. Computational Screening of Efficient Single-Atom Catalysts Based on

4 Graphitic Carbon Nitride $\left(\mathrm{g}_{-} \mathrm{C}_{3} \mathrm{~N}_{4}\right)$ for Nitrogen Electroreduction. Small Methods 3, 1-9 $5 \quad$ (2019).

6 33. Zhang, B. et al. Homogeneously dispersed multimetal oxygen-evolving catalysts. Science. $7 \quad 352,333-337$ (2016).

8 34. $\mathrm{Xu}, \mathrm{R}$. et al. $\mathrm{Ni}_{3} \mathrm{Se}_{2}$ nanoforest/Ni foam as a hydrophilic, metallic, and self-supported 9 bifunctional electrocatalyst for both $\mathrm{H}_{2}$ and $\mathrm{O}_{2}$ generations. Nano Energy 24, 103-110 10 (2016).

11 35. Wang, Y. et al. Lattice-Strain Engineering of Homogeneous $\mathrm{Ni}_{0.5} \mathrm{Se}_{0.5}$ Core-Shell 12 Nanostructure as a Highly Efficient and Robust Electrocatalyst for Overall Water Splitting. 13 Adv. Mater. 32, 1-10 (2020).

14 36. Zhai, P. et al. Engineering active sites on hierarchical transition bimetal oxides/sulfides 15 heterostructure array enabling robust overall water splitting. Nat. Commun. 11, 1-12 (2020).

16 37. Diao, J. et al. Interfacial Engineering of $\mathrm{W}_{2} \mathrm{~N} / \mathrm{WC}$ Heterostructures Derived from Solid17 State Synthesis: A Highly Efficient Trifunctional Electrocatalyst for ORR, OER, and HER. 18 Adv. Mater. 32, 1-11 (2020). 
1 38. Jia, Y. et al. A Heterostructure Coupling of Exfoliated Ni-Fe Hydroxide Nanosheet and

2 Defective Graphene as a Bifunctional Electrocatalyst for Overall Water Splitting. Adv.

$3 \quad$ Mater. 29, 1-8 (2017).

4 39. Shang, X. et al. Carbon fiber cloth supported interwoven $\mathrm{WS}_{2}$ nanosplates with highly

5 enhanced performances for supercapacitors. Appl. Surf. Sci. 392, 708-714 (2017).

6 40. $\mathrm{Yu}, \mathrm{H}$. et al. High performance in electrochromic amorphous $\mathrm{WO}_{\mathrm{x}}$ film with long-term 7 stability and tunable switching times via $\mathrm{Al} / \mathrm{Li}$-ions intercalation/deintercalation.

$8 \quad$ Electrochim. Acta 318, 644-650 (2019).

9 41. Yao, Y. et al. Synthesis of $\mathrm{Cs}_{\mathrm{x}} \mathrm{WO}_{3}$ nanoparticles and their NIR shielding properties. Ceram.

$10 \quad$ Int. 44, 13469-13475 (2018).

11 42. Tang, C. et al. Coordination Tunes Selectivity: Two-Electron Oxygen Reduction on High-

12 Loading Molybdenum Single-Atom Catalysts. Angew. Chemie. Int. Ed. 59, 9171-9176

13 (2020).

14 43. Tan, S. M. \& Pumera, M. Bottom-up Electrosynthesis of Highly Active Tungsten Sulfide

15 (WS $\left.{ }_{3-\mathrm{x}}\right)$ Films for Hydrogen Evolution. ACS Appl. Mater. Interfaces 8, 3948-3957 (2016).

16 44. Li, M. et al. Ni Strongly Coupled with $\mathrm{Mo}_{2} \mathrm{C}$ Encapsulated in Nitrogen-Doped Carbon Nanofibers as

17 Robust Bifunctional Catalyst for Overall Water Splitting. Adv. Energy Mater. 9, 1803185 (2019).

18 45. Li, X. et al. Sequential Electrodeposition of Bifunctional Catalytically Active Structures in

$19 \mathrm{MoO}_{3} / \mathrm{Ni}-\mathrm{NiO}$ Composite Electrocatalysts for Selective Hydrogen and Oxygen Evolution.

$20 \quad$ Adv. Mater. 32, 1-10 (2020). 
46. Yan, J. et al. Single atom tungsten doped ultrathin $\alpha-\mathrm{Ni}(\mathrm{OH})_{2}$ for enhanced electrocatalytic water oxidation. Nat. Commun. 10, 1-10 (2019).

3 47. Luo, Z. et al. Chemically activating $\mathrm{MoS}_{2}$ via spontaneous atomic palladium interfacial 4 doping towards efficient hydrogen evolution. Nat. Commun. 9, 1-8 (2018).

5 48. Huang, P. Y. et al. Grains and grain boundaries in single-layer graphene atomic patchwork quilts. Nature 469, 389-392 (2011).

49. Jiang, J. et al. Atomic-level insight into super-efficient electrocatalytic oxygen evolution on

8 iron and vanadium co-doped nickel (oxy)hydroxide. Nat. Commun. 9, 1-12 (2018).

9 50. Li, Z. Y. et al. New insights into designing high-rate performance cathode materials for 10 sodium ion batteries by enlarging the slab-spacing of the Na-ion diffusion layer. J. Mater.

11 Chem. A 4, 3453-3461 (2016).

12 51. Van Der Zande, A. M. et al. Grains and grain boundaries in highly crystalline monolayer 13 molybdenum disulphide. Nat. Mater. 12, 554-561 (2013).

14 52. $\mathrm{Mu}, \mathrm{C}$. et al. Rational Design of Spinel Cobalt Vanadate Oxide $\mathrm{Co}_{2} \mathrm{VO}_{4}$ for Superior 15 Electrocatalysis. Adv. Mater. 32, 1-8 (2020).

16 53. Ran, J. et al. Modulation of Electronics of Oxide Perovskites by Sulfur Doping for 17 Electrocatalysis in Rechargeable Zn-Air Batteries. Chem. Mater. 32, 3439-3446 (2020).

18 54. $\mathrm{Yu}, \mathrm{L}$. et al. $\mathrm{Cu}$ nanowires shelled with $\mathrm{NiFe}$ layered double hydroxide nanosheets as 19 bifunctional electrocatalysts for overall water splitting. Energy Environ. Sci. 10, 1820-1827 (2017). 
1 55. Sheng, W., Myint, M., Chen, J. G. \& Yan, Y. Correlating the hydrogen evolution reaction

2 activity in alkaline electrolytes with the hydrogen binding energy on monometallic surfaces.

$3 \quad$ Energy Environ. Sci. 6, 1509 (2013).

4 56. Ling, T. et al. Activating cobalt (ii) oxide nanorods for efficient electrocatalysis by strain 5 engineering. Nat. Commun. 8, 1509 (2017).

6 57. Zhao, C. et al. Insights into the electronic origin of enhancing the catalytic activity of $\mathrm{Co}_{3} \mathrm{O}_{4}$

7 for oxygen evolution by single atom ruthenium. Nano Today 34, 100955 (2020).

8 58. Segall, M. D. et al. First-principles simulation: Ideas, illustrations and the CASTEP code. $J$.

$9 \quad$ Phys. Condens. Matter 14, 2717-2744 (2002).

10 59. Perdew, J. P., Burke, K. \& Ernzerhof, M. Generalized gradient approximation made simple.

11 Phys. Rev. Lett. 77, 3865-3868 (1996).

12 60. Hamann, D. R., Schlüter, M., \& Chiang, C. Norm-conserving pseudopotentials. Physical

13 Review Letters, 43, 1494 (1979).

14 61. Li, H. et al. Design of $\mathrm{Pt} / \mathrm{t}-\mathrm{ZrO}_{2} / \mathrm{g}-\mathrm{C}_{3} \mathrm{~N}_{4}$ efficient photocatalyst for the hydrogen evolution 15 reaction. Appl. Catal. B Environ. 251, 305-312 (2019).

16 62. Wu, Y. et al. Unexpected monoatomic catalytic-host synergetic OER/ORR by graphitic 17 carbon nitride: Density functional theory. Nanoscale 11, 5064-5071 (2019).

\section{Additional information}

19 Supplementary Information accompanies this paper at http://www.nature.com/ 20 naturecommunications 


\section{Competing financial interests}

2 The authors declare no competing financial interests. 


\section{Supplementary Files}

This is a list of supplementary files associated with this preprint. Click to download.

- Supportinglnformation.pdf 